In press: Aging, Neuropsychology, and Cognition (accepted $16^{\text {th }}$ February, 2019).

\title{
Multimodal coding and strategic approach in young and older adults' visual working memory performance.
}

\author{
Louise A. Brown Nicholls ${ }^{1}$ and Brad English ${ }^{2}$
}

1. Corresponding Author: School of Psychological Sciences \& Health, University of Strathclyde, 40 George Street, Glasgow, G1 1QE. Email: 1.nicholls@ strath.ac.uk; telephone +44 (0)141548 2661. ORCID ID: 0000-0003-3520-6175.

2. Nottinghamshire Healthcare NHS Foundation Trust, Clinical Psychology Department, Fern House, Highbury Hospital, Highbury Road, Nottingham, NG6 9DR. Email: Brad.English@nottshc.nhs.uk; telephone +44 (0)115 8542206.

To cite: Nicholls, L.A.B., \& English, B. (in press). Multimodal coding and strategic approach in young and older adults' visual working memory performance. Aging, Neuropsychology, and Cognition.

\section{Author Notes}

Some of this research was conducted while the authors were at Nottingham Trent University. We thank Catherine Blackburn and Emma Kerr for their assistance with some of the data collection. 


\begin{abstract}
Visual working memory (WM) was investigated in young (18-35 yrs) and older (63-88 yrs) adults by assessing use of visual and verbal processing, and strategic approach. Experiment 1 comprised a visual interference paradigm, to investigate visual rehearsal during an abstract visual WM task. Results suggested both groups used a visual strategy, but older adults struggled more when visual interference was administered first, perhaps due to difficulty developing non-visual strategies. In Experiment 2, a more meaningful task version was additionally administered, offering greater opportunity for multimodal coding. Despite the marked effect of age, both groups benefited from semantic availability to the same extent. Young adults reported a verbal strategy more than older adults, who reported less verbal labelling and more visual refreshing, and a less efficient approach overall. The results highlight age-related limitations in visual WM capacity and strategy use, but show potential for compensation, and a role for task practice.
\end{abstract}

Keywords: visual working memory; strategy; dual and multimodal coding; cognitive aging/ageing; older adults. 
Multimodal coding and strategic approach in young and older adults' visual working memory performance.

Early investigations of short-term ('working') memory were largely focused upon the verbal domain. However, the volume of research on visuo-spatial working memory has seen a significant increase in the last two decades (for reviews, see Luck \& Vogel, 2013; Ma, Husain, \& Bays, 2014). In parallel, research investigating older adults' working memory performance has also been increasing, producing evidence of age-related declines in both the visuo-spatial and verbal domains (e.g. Bopp \& Verhaeghen, 2005; Hedden, \& Gabrieli, 2004; Park et al., 2002). It is important to understand the underlying cognitive mechanisms of agerelated declines in working memory (e.g. processing speed, attention/executive resources, storage capacity limitations). Research targeting visual working memory performance is anticipated to help support broader theoretical understanding of cognitive aging mechanisms, because visual working memory appears particularly vulnerable to aging.

\section{Aging effects on visual working memory}

It has been well established that aging negatively impacts working memory performance (Hedden, \& Gabrieli, 2004; Park et al., 2002; Reuter-Lorenz \& Lustig, 2016). Fluid cognitive abilities like working memory are typically the most sensitive to age-related cognitive decline, as they involve more speeded and/or more complex online processing than crystallized abilities such as vocabulary and general knowledge. Visuo-spatial working memory is particularly age-sensitive (e.g. Brown, 2016; Jenkins, Myerson, Joerding, \& Hale, 2000; Murre, Janssen, Rouw, \& Meeter, 2013; Myerson, Hale, Rhee, \& Jenkins, 1999; Noack, Lövdén, \& Lindenberger, 2012; Swanson, 2017). Furthermore, specifically visual working memory (i.e. memory for visual details such as visual patterns, orientations, and colors) has exhibited marked age-related deficits (Beigneux, Plaie, \& Isingrini, 2007; Brown, Brockmole, Gow, \& Deary, 2012; Bruyer \& Scailquin, 1999; Johnson, Logie, \& Brockmole, 2010; Leonards, Ibanez, \& Giannakopoulos, 2002; Logie \& Maylor, 2009; Peich, Husain, \& Bays, 2013; Smith, Park, Cherry, \& Berkovsky, 1990). For example, using a visual matrix task to assess capacity (e.g. Brown, Forbes, \& McConnell, 2006; Brown et al., 2012; Brown \& Wesley, 2013; Della Sala, Gray, Baddeley, Allamano, \& Wilson, 1999; Della Sala, Gray, Baddeley, \& Wilson, 1997; Orme, Brown, \& Riby, 2017; Riby \& Orme, 2013), Logie and Maylor (2009) demonstrated that, among a range of other fluid abilities (e.g. visuo-spatial 
binding, prospective memory, verbal working memory), visual working memory displayed the steepest decline across the adult lifespan (see also Murre et al., 2013; Swanson, 2017). In this span-type task, participants briefly view a checkered pattern and, after a short delay (typically up to $10 \mathrm{~s}$ ) participants attempt to recall the pattern, either by clicking on individual cells on a computer screen, or crossing the cells on blank paper templates. The patterns are initially quite small (e.g. 2 x 2 matrix), but increase in size and complexity as the task progresses. Thus, the task measures 'capacity', in terms of the largest pattern size that the participant is reliably able to recall correctly. The age-related decline in capacity appears to be linear, and begins early in the adult lifespan (i.e., the early 20s; Bruyer \& Scailquin, 1999; Johnson et al., 2010; Logie \& Maylor, 2009). Beigneux et al. (2007) even suggested that visual working memory is more age-sensitive than spatial-sequential working memory, further highlighting that memory for a simultaneously presented visual array is particularly challenging for older people.

However, the challenge may not simply be related to a reduced visual working memory storage capacity per se. Using behavioural and ERP methods to investigate the encoding, maintenance, and retrieval stages of a color change detection task, Ko et al. (2014) found that older adults appeared to engage the same sensory encoding processes, and store the same number of objects during maintenance, as young adults. However, older adults retained stimuli at a lower resolution. Furthermore, at the retrieval stage of their change detection task, older adults did not appear to experience familiarity or recollection to the same extent as young adults, and were shown subsequently to engage in more post-retrieval monitoring and verification processes. The authors concluded that, due to lower quality representations, older adults struggle to retrieve visual stimuli as accurately as young adults. Indeed, Peich et al. (2013) also demonstrated less precision in older adults' visual working memory, but further showed that age was more strongly related to precision under higher memory load ( 3 objects vs 1).

Interestingly, using computational modelling of visuo-spatial change detection task performance, Noack et al. (2012) found age effects only for multiple object arrays ( 3 or 5 objects vs 1$)$, at both short (100ms) and long (1000ms) retention periods. Data modeling suggested that age negatively affects both discriminal dispersion (indexing a decreased signal-to-noise ratio, or, less distinct representations) and asymptotic discrimination performance (indexing short-term memory capacity). Noack et al. therefore concluded that age mainly affects the encoding stage of their task, and that both reduced storage capacity and less distinct neural activation can account for age-related limitations in visual working 
memory. Using time-accuracy function analysis (Kliegl, Mayr, \& Krampe, 1994), Guest, Howard, Brown, and Gleeson (2015) observed age-related slowing of visual processing, specifically with multiple object arrays. This slowing was observed when the task involved processing and filtering out distractors at encoding, and also when required to encode more than one object into visual working memory for possible recall. Thus, there are age-related limitations in both the capacity for, and quality of, information encoding and storage in visual working memory.

\section{Age-related scaffolding of visual working memory}

At the neural level, there is age-related visual cortex degeneration. Older adults exhibit decreased occipital cortex activation during visual perception and memory tasks, as well as less specific or distinctive neural activation (Davis, Dennis, Daselaar, Fleck, \& Cabeza, 2008; Grady, 1996; Grady et al., 1994; see also Li, Lindenberger, Sikström, 2001; Li \& Sikström, 2002; Spreng, Wojtowicz, \& Grady, 2010). Decreased specificity has been described as agerelated dedifferentiation (Carp, Park, Polk, \& Park, 2011; Park et al., 2004, 2012; Payer et al., 2006). Neural specificity predicts $30 \%$ of the variance in higher-order cognitive functioning (i.e., fluid intelligence; Park, Carp, Hebrank, Park, \& Polk, 2010; see also Geerligs, Maurits, Renken, \& Lorist, 2014), supporting the notion that, to some extent, dedifferentiation underlies age-related decline in processing-intensive cognitive functioning. However, much of the variance still remains to be explained by other factors, which could potentially help to counteract the age-related reduction in neural distinctiveness. For example, level of task demand (Carp, Gmeindl, and Reuter-Lorenz, 2010) and individual differences in processing and working memory capacity (Schneider-Garces, Gordon, Brumback-Peltz, \& Shin, 2010) are likely to be involved.

Promisingly, even when specialized cognitive resources are compromized with age, older adults have the potential to compensate for, or 'scaffold' these functions, using more generalized central executive resources (Park \& Reuter-Lorenz, 2009; Reuter-Lorenz \& Park 2010; see also Cabeza, Anderson, Locantore, \& McIntosh, 2002; Reuter-Lorenz \& Cappell, 2008; Reuter-Lorenz \& Lustig, 2016). Furthermore, the scaffolding process benefits from health and lifestyle factors, such as cognitive and social engagement, and physical activity (Reuter-Lorenz \& Park, 2014; Reuter-Lorenz \& Lustig, 2016), accounting for some of the individual differences in cognitive aging success. The Scaffolding Theory of Aging and Cognition (Park \& Reuter-Lorenz, 2009; Reuter-Lorenz \& Park 2010, 2014) would predict 
that, even when neural degeneration has taken place, for example in visual cortex, cognitive decline is not inevitable, due to the recruitment of supporting neural resources. Thus, higherfunctioning older adults may achieve better performance due to compensatory, more distributed patterns of neural activation (e.g. Cabeza et al., 2002; Burianová, Lee, Grady, \& Moscovitch, 2013) which could be related to strategy development and execution (e.g. Logie, 2011, 2012).

A compelling example can be found in the strategy training research by Nyberg et al. (2003). Young and older people were trained in the method of loci as a strategy to support verbal working memory, involving associating to-be-remembered words with locations within a known spatial layout (map; e.g. Bower, 1970). Young participants improved after training, as expected, whereas the older people showed no benefit. However, the older participants were split into two groups, based on the extent of neural engagement associated with strategy use (i.e. spatial cortex activation). Older adults who showed this functional activity exhibited improved working memory capacity, like the young adults, but the older adults who showed no such neural activity performed more poorly after training. Thus, there are ageing effects on strategy execution, and clear individual differences in older people's ability to implement and benefit from cognitive strategies. These qualitative differences have direct implications for our theoretical understanding of quantitative differences, such as neural activation patterns, cognitive slowing, etc. (Lemaire, 2016). It is therefore fundamentally important to investigate top-down influences on cognition, such as strategic approach, if we are to achieve a complete understanding of cognitive aging.

\section{Multimodal coding and strategic approach}

Memory is typically more successful when the stimuli may be encoded using multiple modalities. In the long-term memory context, Paivio's dual coding theory $(1971 ; 1991)$ states that words will be better recalled when they are higher in imageability (i.e. more 'concrete', such as 'jacket'), as compared with more abstract words (e.g. 'jealous'). Similarly, abstract visual stimuli are better recalled from long-term memory when there is a meaningful, verbal context provided (Bower, Karlin, \& Dueck, 1975; Santa, 1975; Verhaeghen, Palfai, \& Johnson 2006). By extension, Brown et al. (2006; see also Mammarella, Giofrè, Caviola, Cornoldi, \& Hamilton, 2014; Postle, \& Hamidi, 2007; Riby \& Orme, 2013) showed that short-term memory for abstract visual patterns is also superior when the stimuli are more 
readily verbally encoded, although the associated meaningfulness may account for the benefit rather than the verbalization itself (Brown \& Wesley, 2013).

Although there is currently limited evidence on the topic, Lemaire (2016) highlighted that, where we observe cognitive aging effects, it is likely that differences in strategy selection will also be observed. A 'strategy' may be considered a method, procedure, or set of procedures used by an individual to achieve a goal (Lemaire, 2016). In the present context, the goal would be to recall the visual appearance of a previously seen array, and potential strategies include actively refreshing the visual image, or relating it to a stored representation (i.e. visual semantics; Logie, 2011).

Undoubtedly, we require evidence regarding spontaneous strategy use in older people, but the concept of compensation and scaffolding is not only relevant to older adults' cognitive performance. Strategy use in working memory develops from childhood into adulthood (Swanson, 2017), and there are individual differences in the cognitive strategies recruited by young adults. For example, Logie, Della Sala, Laiacona, Chalmers, and Wynn (1996) showed that healthy adults' strategy use varies during a working memory task. Furthermore, the cognitive effects observed across individuals (e.g. the extent to which participants display word length effects) depends upon their reported strategy use (e.g. verbal rehearsal or visualization). Specifically considering visual working memory, and performance of the visual matrix task used in the present study (Brown et al., 2006), Brown and Wesley (2013) investigated young adults' use of a variety of potential strategies, including explicit visual rehearsal, verbal coding, 'counting up' cells, and combining visual and verbal strategies. While Logie et al. categorized the participants into different strategies, Brown and Wesley asked participants to rate the extent to which they implemented the range of strategies that were queried. Intriguingly, Logie et al. observed numerous individuals who reported using 'mixed' strategies. Like the findings of Logie et al., Brown and Wesley showed that, not only was there clear individual variation in the extent to which participants reported using the different strategies, but strategy use interacted with the properties of the task (abstract or more meaningful stimuli). Those who reported combining visual and verbal strategies, therefore approaching the task more actively and flexibly, had a larger overall capacity. Furthermore, those who did not report such an approach benefited considerably more from the availability of visual semantics, possibly due to their automatic activation (Logie, 2011; see also Campoy, Castellà, Provencio, Hitch, \& Baddeley, 2015). Thus, in young adults, self-reported strategic approach is related to visual working memory capacity and interacts with the properties of the task. 
Particularly given the findings by Nyberg et al. (2003), aging could influence the use of task strategies in visual working memory and may partially account for the effect of aging on capacity. Strategy use is now increasingly mentioned in discussions of aging and cognition, and particularly relating to the input of central executive resources to working memory performance (e.g. Reuter-Lorenz \& Lustig, 2016; Reuter-Lorenz \& Park, 2014). Strategy use has been considered across a range of domains, including episodic memory (e.g. Hinault, Lemaire, \& Touron, 2017; Kuhlmann, \& Touron, 2012; Naveh-Benjamin, Brav, \& Levy, 2007), and working memory (Bailey, Dunlosky, \& Hertzog, 2009; Fiore, Borella, Mammarella, \& De Beni, 2012; Touron, Oransky, Meier, \& Hines, 2010). In the context of arithmetic problem solving, these issues have been researched relatively intensively (e.g. Duverne \& Lemaire, 2004; Hodzik, \& Lemaire, 2011; see Lemaire, 2016, for a review), with findings occasionally showing that older people have a smaller repertoire than young adults. However, other studies have shown that older adults have knowledge of just as many different strategies as young adults, but that they execute fewer strategies that may be more exhaustive (i.e. relatively inefficient) and are less likely than young adults to adapt their strategy according to the specific problem (Lemaire, 2016).

Recent findings in the study of verbal working memory have been mixed. On one hand, set-by-set strategy reports have been found not to explain age-related variance in working memory capacity (Bailey et al., 2009) while, on the other hand, Touron et al. (2010) observed that effective strategy use disproportionately benefitted older adults' performance. In the context of a spatial-sequential working memory task (visuo-spatial updating), Fiore et al. (2012) argued that older adults may make some use of explicit rehearsal, but that they mostly rely on a low-effort recency strategy to drive memory for spatial sequences. However, strategy was inferred from the patterns of performance across serial position, rather than being directly assessed. Thus, there is limited evidence that strategy may be implicated in the effects of aging in visuo-spatial working memory, but research is required to assess the potential effects of aging on the use of a variety of directly relevant strategies in visuo-spatial working memory. Furthermore, to our knowledge, this is the first attempt to address strategy in the context of age-sensitive visual working memory in particular. Therefore, using interference paradigms, we aimed to establish the working memory mechanisms drawn upon in young and older adult during a visual working memory task. Additionally, we aimed to determine the spontaneous strategy use reported by young and older adults, across a range of potentially useful strategies for the task at hand. 


\section{Summary}

The influence of aging on strategy execution in working memory has received relatively little direct investigation and, to our knowledge, has not yet been assessed specifically in the context of age-sensitive visual working memory. The current investigations were aimed at identifying the extent to which young and older people employ task-relevant strategies in the context of a visual working memory task, using interference paradigms and strategy self-report. In Experiment 1, we investigated young and older adults' use of visual rehearsal via a visual interference paradigm. In Experiment 2, using a verbal interference paradigm and stimuli with low and high semantic availability, we investigated the extent to which the two age groups relied upon verbal rehearsal and could benefit from the availability of meaning. Additionally, in Experiment 2, we queried spontaneous use of a range of visual and verbal task-relevant strategies, in order to investigate the relationships with task performance and the effect of aging.

\section{EXPERIMENT 1}

This experiment was aimed at establishing, using an interference paradigm, the extent to which young and older adults rely on visual storage to perform a visual working memory task. In the context of age-related degradation in visual cortex functioning, and the marked age-related deficits in capacity, it is possible that the two age groups may rely differently on a visual rehearsal strategy. Specifically, younger people may show more sensitivity to visual interference than older people, who may not be able to rely upon maintenance of a mental image.

During performance of a visual working memory task, then, reliance on a mental image was investigated by employing a visual interference paradigm, in which visual noise was viewed during the maintenance period. It was predicted that, if a participant is relying on visual storage, their performance should be sensitive to the presence of visual interference. Importantly, the visual interference (dynamic visual noise; DVN) was not attentionally demanding, so as not to interfere with executive functioning (Quinn \& McConnell, 1996a,b), and has been shown to reduce visual imagery and working memory for visual details (Borst, Ganis, Thompson, \& Kosslyn, 2012; Darling, Della Sala, \& Logie, 2009; Dean, Dewhurst, \& Whittaker, 2008; McConnell \& Quinn, 2004; Vasques, Garcia, \& Galera, 2016). Thus, a small but reliable effect of passively viewing visual noise was expected, at least in the young 
adults. However, if older people tend not to rely upon visual storage, they will be less sensitive to the interference, resulting in an interaction between age group and interference condition, with only the young adults exhibiting an effect.

\section{Methods}

\section{Participants}

The study was ethically approved by the respective ethics committees at Nottingham Trent University and the University of Strathclyde, and participants provided written informed consent. There were 44 young and older participants. The young participants were 9 men and 13 women, aged $18-35$ years $(M=23.14, S D=4.95)$ and with a mean years of education of $16.09(S D=1.85)$. The older adults included 5 men and 17 women, aged 63-88 years $(M=$ $72.18, S D=7.39$; mean years of education $=13.64, S D=4.52$ ). The young adults had significantly more years of education than the older adults, $t(27.8)=2.36, p=.026$, however this is a commonly observed cohort effect (e.g. Guest et al., 2015). The older participants volunteered on the basis of being generally healthy and living independently in the community, however, cognitive functioning was specifically screened using the Mini-Mental State Examination (Folstein, Folstein, \& McHugh, 1975). All older participants scored within the healthy range $(M=28.52, S D=1.33 ; \min =25, \max =30)$. All participants reported normal or corrected-to-normal vision, and no memory problems.

\section{Design}

A $2 \times 2$ mixed factorial design was used to investigate the effects of age group (young, older), and interference (control, visual interference; repeated measures) on visual working memory capacity. The dependent variable was mean span, which is a more sensitive measure than maximum span achieved. This was calculated by taking the mean size of the last three correctly recalled patterns for each participant in each of the two task versions (e.g. Brown et al., 2006).

\section{Materials}

Mini-Mental State Examination (Folstein et al., 1975): This is a brief assessment of general cognitive functioning, which involves testing participants' orientation to time and place, attention, memory, language, and instruction-following. A score of 24 or above (out of 30) indicates normal cognitive functioning. 
Modified Visual Patterns Test: The Visual Patterns Test (Della Sala et al., 1997; Della Sala et al., 1999) is a test of short-term visual memory. Recall of each abstract, black-and-white checkered pattern may be either immediate or delayed (typically up to $10 \mathrm{~s}$ ), in order to place more demands on working memory (e.g. requiring more active rehearsal). Following previous research (Brown \& Wesley, 2013; Brown et al., 2012; see also Riby \& Orme, 2013; White \& Grant, 2017), the present experiment employed the modified version of the test (Brown et al., 2006), which was designed to limit the availability of verbal and semantic coding. The stimuli consisted of half black and half white cells (see Figure 1), ranging in their level of complexity from two (two black cells to be remembered) to fifteen, and there were three patterns at each level. The task was computerized in order to control presentation and timings, and was administered using E-Prime 2.0 (Psychology Software Tools, Inc.). Beyond the differences in selected stimuli and the computerized presentation, administration was broadly similar to the originally published test, in terms of presentation time, maintenance period, and recall method (Della Sala et al., 1997; Della Sala et al., 1999).

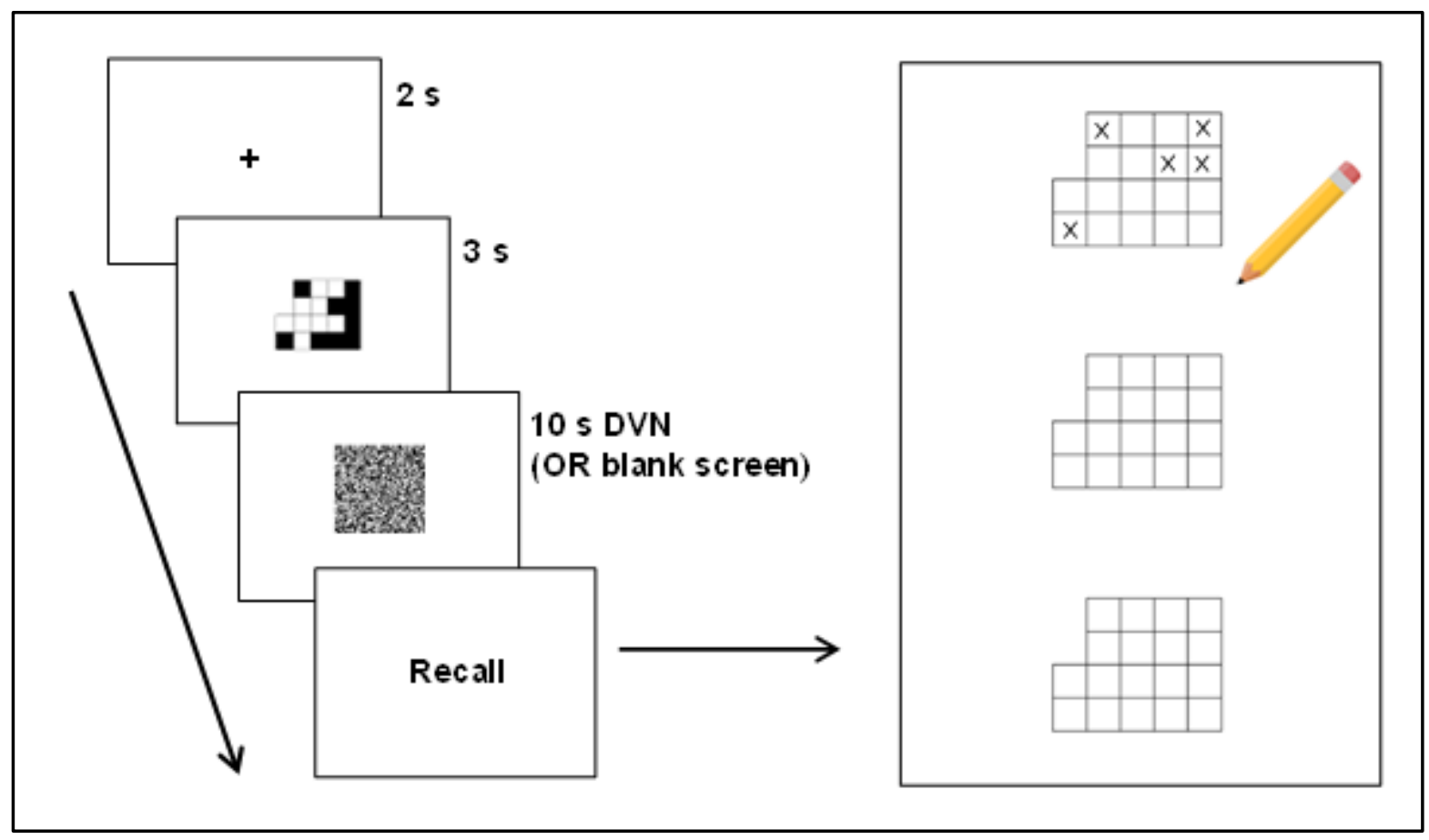

Figure 1: Experiment 1 procedure. In a given trial, participants were shown a visual pattern for $3 \mathrm{~s}$. They then viewed either the blank computer screen (control condition) or the dynamic visual noise (DVN; visual interference) condition for $10 \mathrm{~s}$. Using a blank paper template, participants then attempted to recall the pattern by crossing out the cells that they remembered as having been black. Note, stimuli are not drawn to size, and the recall templates were printed on standard A4 paper. 
Visual interference: The visual interference involved participants viewing dynamic visual noise (DVN; Figure 1; see also Brown, 2016). The DVN appears as a computergenerated display of small black and white 'dots' (each 16 pixels in area) which randomly change between black and white, continuously across the array. The array comprised $80 \times 80$ 'dots', thus measuring 320 x 320 pixels (which equated to approximately $12 \mathrm{~cm}^{2}$ ). The rate of change amongst the dots was relatively high in the context of previous literature, at $30 \%$ (1920 dots) changing per second (Dean, Dewhurst, Morris, \& Whittaker, 2005; McConnell \& Quinn, 2000).

\section{Procedure}

The older participants first completed the MMSE (Folstein et al., 1975), which took approximately five minutes. The young participants immediately began with the visual working memory task. All participants completed both the control and visual interference versions of the visual memory task (Brown et al., 2006; see also Della Sala et al., 1997), and administration order was counterbalanced across participants within each age group. After receiving standard instructions and up to three practice trials from level four of the task (Brown et al., 2006; Brown et al., 2012; Della Sala et al., 1997), the first task version was conducted. Given the previously demonstrated marked difference in capacity across the two age groups with this task (Beigneux et al., 2007; Brown et al., 2006; Brown et al., 2012; Brown \& Wesley, 2013; Logie \& Maylor, 2009), the young adults began at level four, whereas the older adults began at level two. This also served to equalize the typical duration of the task across age groups. Note, the span nature of this task highlights the memory challenge that sets in as the patterns increase in size, and successful performance in the initial levels demonstrates the ability of both age groups to view and encode the patterns sufficiently.

Each trial in the control task commenced with the participant pressing the space bar, then presentation of a fixation cross for $2 \mathrm{~s}$ (Figure 1). The memory stimulus was then displayed upon a white background for $3 \mathrm{~s}$, followed by a maintenance period of $10 \mathrm{~s}$, during which the screen was blank (white). Participants were specifically asked to continue viewing the screen during this maintenance period. After the delay, the word recall was presented, indicating that it was time to attempt recall. Participants were asked to reproduce the pattern on blank paper templates, by placing an $X$ in the cells they remembered as having been black. Each task version terminated when the participant failed to recall completely correctly at least one trial from a given level. After completing the first task version, a short break was offered to participants 
before progressing to the second one. The interference task version was the same as the control task, except that DVN was displayed centrally on the screen during the delay. Again, participants were specifically instructed to view the screen during this time.

\section{Results}

The order of administration of the two versions was found to be important, therefore the data from each condition, including administration order, are illustrated in Figure $2^{1}$.

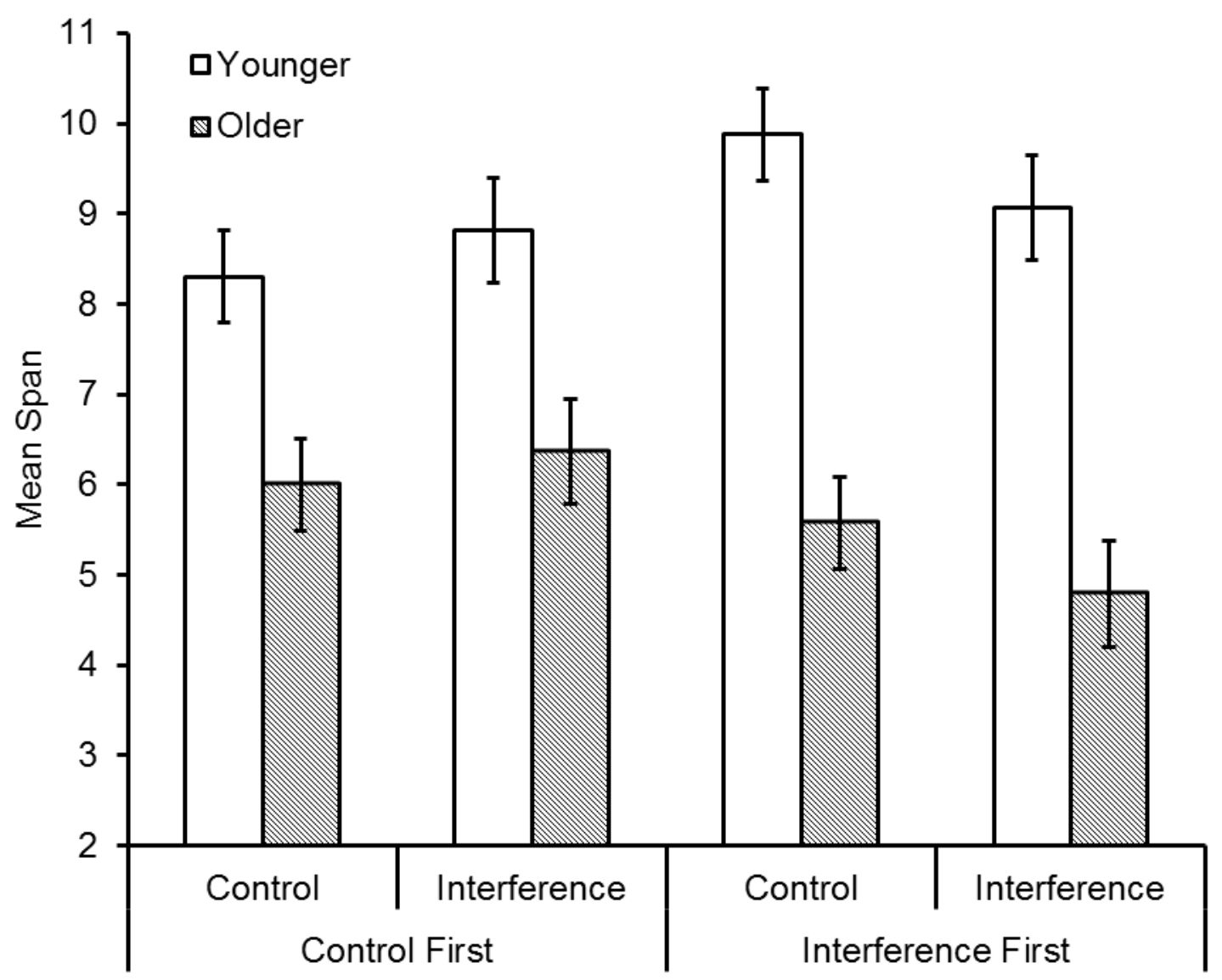

Figure 2: Mean span data ( \pm SE) from Experiment 1, as a function of age group, interference condition, and administration order.

The data were analyzed using a 2 (age group; young, older) $\times 2$ (visual interference; control, interference) $\times 2$ (administration order; control first, interference first) mixed factorial

\footnotetext{
${ }^{1}$ Note that, when administration order is not included in the analysis, there is only a significant main effect of age group, $F(1,42)=41.13, M S E=5.95, p<.001, \eta^{2} p=.50$ (all other $p>.40$ ).
} 
Analysis of Variance (ANOVA). There was a significant main effect of age group, $F(1,40)=$ 42.61, $M S E=5.74, p<.001, \eta^{2} \mathrm{p}=.52$, and a significant interaction between interference and administration order, $F(1,40)=9.99, M S E=.849, p=.003, \eta^{2}{ }_{p}=.20($ Figure 3$)$.

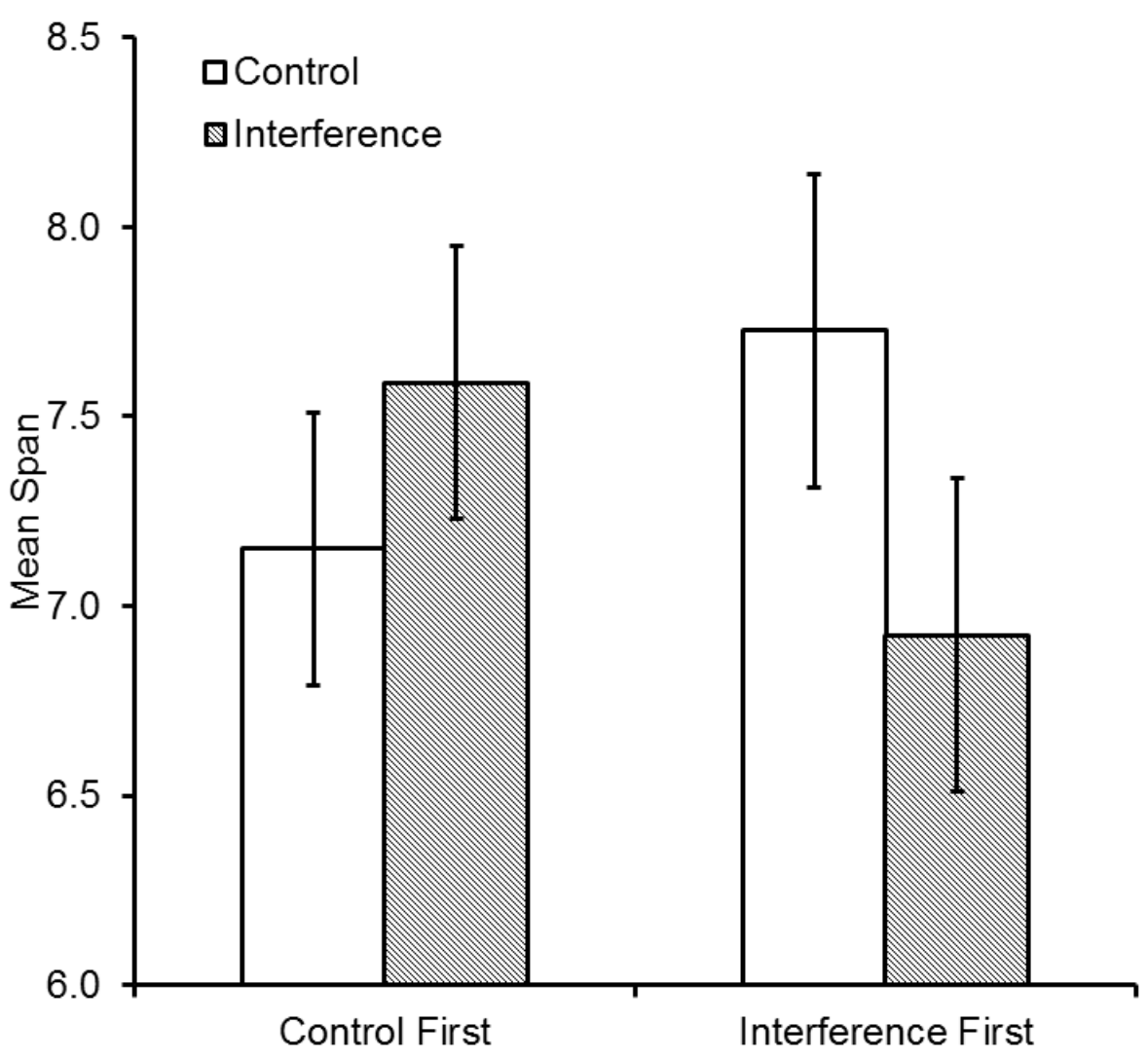

Figure 3: Interaction between interference and administration order. Data represent mean $\operatorname{span}( \pm \mathrm{SE})$.

To follow up this interaction, Bonferroni-corrected paired t-tests were carried out to assess the effect of interference within each administration order group. There was no significant difference between the two interference conditions within those who carried out the control condition first, $t(21)=1.70, p=.104\left(M_{\mathrm{CONTROL}}=7.15, S D=2.08 ; M_{\mathrm{DVN}}=7.59, S D=2.50\right)$. However, there was a significant effect of visual interference in those who carried out that condition first, $t(21)=2.83, p=.010\left(M_{\mathrm{CONTROL}}=7.73, S D=2.71 ; M_{\mathrm{DVN}}=6.93, S D=2.69\right)$.

Additionally, the interaction between age group and administration order was approaching significance, $F(1,40)=3.50, M S E=5.74, p=.069, \eta^{2} \mathrm{p}=.08$ (Figure 4; all other $p>$.36). This was therefore further explored using Bonferroni-corrected independent t-tests. 
There is clearly a reliable age effect overall, but the age effect appears more marked when the interference condition was carried out first, $t(20)=6.89, p<.001\left(M_{\text {YOUNG }}=9.47, S D=1.45\right.$; $\left.M_{\text {OLDER }}=5.18, S D=1.47\right)$, than when the control condition was first, $t(20)=2.94, p=.008$ $\left(M_{\text {YOUNG }}=8.56, S D=2.04 ; M_{\text {OLDER }}=6.18, S D=1.74\right)$.

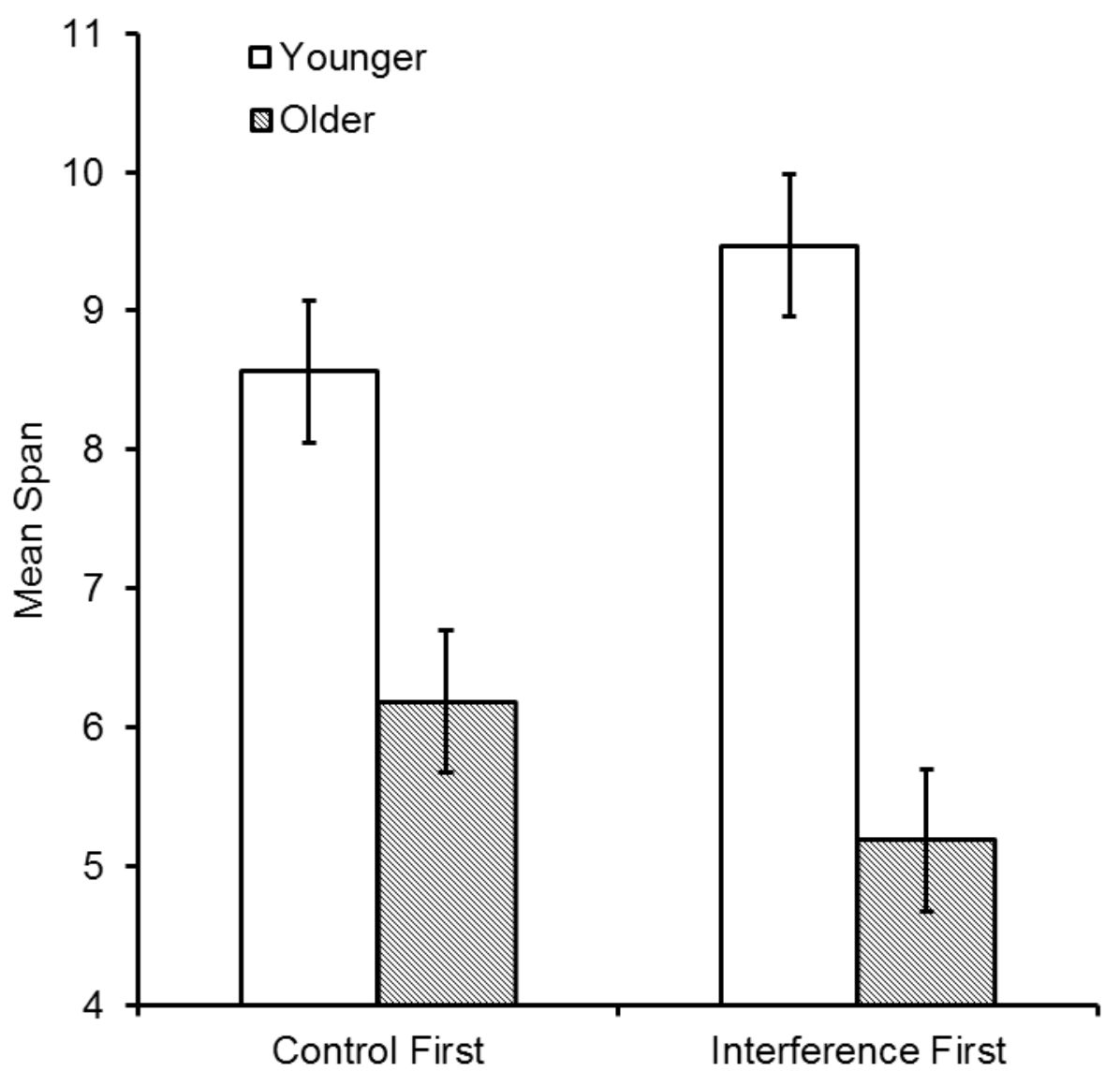

Figure 4: Interaction between age and administration order. Data represent mean span $( \pm$ $\mathrm{SE})$.

\section{Discussion}

The results of Experiment 1 highlight a marked effect of age on visual working memory capacity (e.g., Beigneux et al., 2007; Bruyer \& Scailquin, 1999; Johnson et al., 2010; Leonards et al., 2002; Logie \& Maylor, 2009; Peich et al., 2013; Smith et al., 1990). Furthermore, across both age groups, there was vulnerability to passive visual interference (Borst et al., 2012; Darling et al., 2009; Dean et al., 2008; McConnell \& Quinn, 2004; Vasques et al., 2016), but specifically when that condition was carried out first. Both young 
and older adults therefore appear to rely to some extent upon visual storage. A clear conclusion that can be taken from this experiment, then, is that the visual working memory task appears to be very amenable to broader strategies, particularly over time, given the strong effect of administration order and the interaction with interference. Thus, task performance is likely to be supported by other processes in working memory (Brown et al., 2006; Brown \& Wesley, 2013; Hamilton, Brown, \& Rossi-Arnaud, 2018; Orme et al., 2017; Riby \& Orme, 2013).

Interestingly, the pattern of findings also suggested that young adults may have relatively increased visual working memory capacity, specifically when first experiencing the visual interference condition. In contrast, older adults exhibited more restricted overall capacity in this scenario (Rowe, Hasher, \& Turcotte, 2008). Particularly given the pattern of performance levels within the young age group, the presence of visual interference at the outset of the testing session perhaps encouraged development of compensatory strategies for scaffolding performance in this age group. In contrast, older people may be less able to develop strategies and/or engage wider resources, especially when first engaging with the task (Braver \& West, 2008; Reuter-Lorenz, \& Lustig, 2016). To build upon the results of Experiment 1, which focused on visual rehearsal, in Experiment 2, we sought to investigate the use of other working memory mechanisms. Specifically, Experiment 2 focused on use of verbal rehearsal by using a verbal interference paradigm, as well as semantics by administering two task versions that differ in their extent of meaningful shapes.

\section{EXPERIMENT 2}

Experiment 2 was aimed at investigating young and older adults' reliance on verbal processing, as well as their potential to benefit from the availability of visual semantics (meaning) within visual working memory. We also supplemented the experiment with an end-of-session strategy questionnaire, in order to gain insight into participants' reports of their spontaneous strategy use.

Using the same tasks as in the present experiment, Brown et al. (2006; see also Mammarella et al., 2014; Riby \& Orme, 2013) showed that young adults' visual working memory capacity is reliably larger when the stimuli contain more meaningful shapes. Additionally, Brown and Wesley (2013) found that, within young adults, strategy use varies, and this impacts capacity. While visual rehearsal may be the most fundamental strategy for a 
visual working memory task, incorporating strategies beyond this, such as combining visual and verbal approaches, is related to increased capacity in young people (Postle, D'Esposito, \& Corkin, 2005; Postle \& Hamidi, 2007; Verhaeghen et al., 2006; see also Bower et al., 1975; Paivio, 1971, 1991; Santa, 1975). While Brown and Wesley provided some evidence for automatic activation of semantics (Logie, 2011), the research additionally showed that the benefit associated with more meaningful stimuli requires executive resources. Specifically, when central executive resources were suppressed, the benefit was removed. It is possible that, while semantic memory can be activated automatically at encoding, executive resources may be required for actively combining the different traces (i.e. visual, semantic, verbal, etc.; e.g. see Allen, Havelka, Falcon, Evans, \& Darling, 2015). Indeed, Riby and Orme (2013; see also Orme, Brown, \& Riby, 2017) provided ERP evidence that encoding of high semantic visual stimuli in working memory appears to be more active and strategic than that for low semantic stimuli. As the aging brain may deploy more generalized resources for cognitive task performance (e.g. Cabeza et al., 2002; Park et al., 2012), the age-related deficit in visual working memory may be reduced when more cognitive resources can be recruited to support, or 'scaffold', performance (Park \& Reuter-Lorenz, 2014). Thus, it is possible to predict that the age-related deficit in visual working memory would be smaller in the high meaning, relative to the low meaning, stimuli.

To assess reliance on verbal processing, the verbal interference task took the form of articulatory suppression, which is a well-established technique for suppressing verbal recoding and temporary storage of verbal material (Baddeley, 2007; see also Larsen \& Baddeley, 2003). In young adults, Brown and Wesley (2013) showed that articulatory suppression did not interact with the benefit of meaning, suggesting that the benefit was not due to young adults using verbal working memory to support visual working memory (i.e. explicitly rehearsing verbal labels using the phonological loop of working memory; Baddeley 2007; Logie, 2011). Rather, it was argued that the benefit was most likely due to activated and encoded semantics (see also Delogu, Raffone, \& Belardinelli, 2009; Postle et al., 2005). However, strategies for processing visuo-spatial information may change from childhood through to adulthood (de Ribaupierre, Lecerf, \& Bailleux, 2000), and it is possible that there is further change into older age. Certainly, vocabulary continues to improve across the adult lifespan (Park et al., 2002). Particularly in the context that previous studies have shown visuo-spatial working memory to be more age-sensitive than verbal working memory (Jenkins et al., 2000; Leonards et al., 2002; Myerson et al., 1999), older adults may prefer or rely upon verbal processing more than young adults (e.g. Tournier, \& Postal, 2011). If this is 
the case, then the effect of articulatory suppression would be differential across the two age groups, and this could also interact with the effect of stimulus meaning. Specifically, performance may be worse with articulatory suppression in older adults if they rely upon a verbal approach and are unable to implement it freely. On the other hand, if older adults rely upon a verbal approach, but this hinders rather than benefits visual recall (e.g. Brandimonte, Hitch, \& Bishop, 1992a,b), then suppressing verbalization could potentially even improve performance further.

In Experiment 2, then, we investigated the effects of verbal interference and meaning on visual working memory performance in young and older adults. The effect of meaning was of strong theoretical and applied interest in that, given the marked age-related deficit in visual working memory, older people could potentially benefit more than young people from the availability of more meaningful information, which allows for incorporating more processing resources. Furthermore, if a differential effect of articulatory suppression was observed, this would indicate age-related differential use of verbalization. Combined with the results of the two age groups' responses to a strategy questionnaire, and the results from the present Experiment 1, this evidence was aimed at establishing an important foundation for progressing our understanding of the role of strategic approach and multimodal coding in young and older adults' visual working memory.

\section{Methods}

\section{Participants}

The study was ethically approved by the same committees detailed in Experiment 1, and participants provided written informed consent. There were 56 young and older participants. The young participants were 14 men and 14 women aged $18-29$ years $(M=23.61, S D=$ $3.19)$, and their mean years of full-time education was $15.74(S D=2.25)^{2}$. Using the Test of Premorbid Functioning - UK (ToPF; Pearson Education, Inc., 2009), the young participants' mean estimated full-scale IQ was $101.32(S D=5.79)$. As per Experiment 1, the older participants volunteered on the basis of being healthy and living independently in the community. Cognitive functioning was again screened using the MMSE (Folstein et al., $1975)$, and all older participants scored within the healthy range $(M=27.93, S D=1.68$, min $=24, \max =30)$. The older adults were 11 men and 17 women, aged 63-91 years $(M=72.86$, $S D=6.44)$, with a mean number of years of education of $14.45(S D=4.48)$ and a mean

\footnotetext{
${ }^{2}$ Note, years of education was missing for one young participant.
} 
estimated IQ of $107.00(S D=9.09)$. Estimated IQ was significantly different between the two age groups, $t(45.8)=2.79, p=.008$. However, this was in the opposite direction of any expected effects of age, and verbal knowledge, on which the ToPF is based, is known to increase through the adult lifespan (Park et al., 2002). All participants reported normal or corrected-to-normal vision, and no memory problems.

\section{Design}

Due to the addition of the variable of task meaning, this experimental design took the form of a 2 (age group; young, older) x 2 (verbal interference; control, articulatory suppression between groups) x 2 (task meaning; low, high - repeated measures) mixed factorial design. The dependent variable was mean span. Participants also completed a strategy questionnaire querying the extent of use of a range of visual and verbal-based strategies, and responses to each question were provided on a 5-point likert scale.

\section{Materials}

Test of Premorbid Functioning - UK: The ToPF (Pearson, 2009) is a brief, standardised word reading task which involves asking participants to read out a list of words which increase in difficulty, due to progressively lower frequency. The ToPF provides estimated IQ (prior to onset of any neurological change).

Modified Visual Patterns Test: As in Experiment 1, the modified Visual Patterns Test was used (Brown et al., 2006; Della Sala et al., 1997; Della Sala et al., 1999). Following previous research (Brown \& Wesley, 2013), both modified versions were administered, which differed in their availability of verbal coding and semantics (i.e. relatively low or high meaning; see Figure 5). Some of the shapes within the high semantic version could be described as relatively basic, having previously attracted verbal labels such as letters, numbers, and symbols, while others were amenable to more elaborate labels than this, such as everyday objects and animals (Brown et al., 2006). Aside from the particular patterns used for each task version, the task was the same as described for Experiment 1.

Strategy questionnaire: A likert-style questionnaire was used to allow participants to self-report the extent to which they used a range of task-relevant strategies during the session (Appendix 1; see also Brown \& Wesley, 2013). The first question asked participants to rate their overall strategic approach along a 5-point, verbal-visual continuum. The second question asked participants the extent to which they combined visual and verbal strategies. The 
remaining three questions asked participants to report the extent to which they relied upon a range of more specific visual and verbal-based strategies. These were: 'counting up' the patterns cells; labelling shapes within patterns (both verbal-based); and refreshing their mental image of the pattern (visual). Responses to the last four questions were all made on a 5-point likert scale from 'always' through to 'never'.

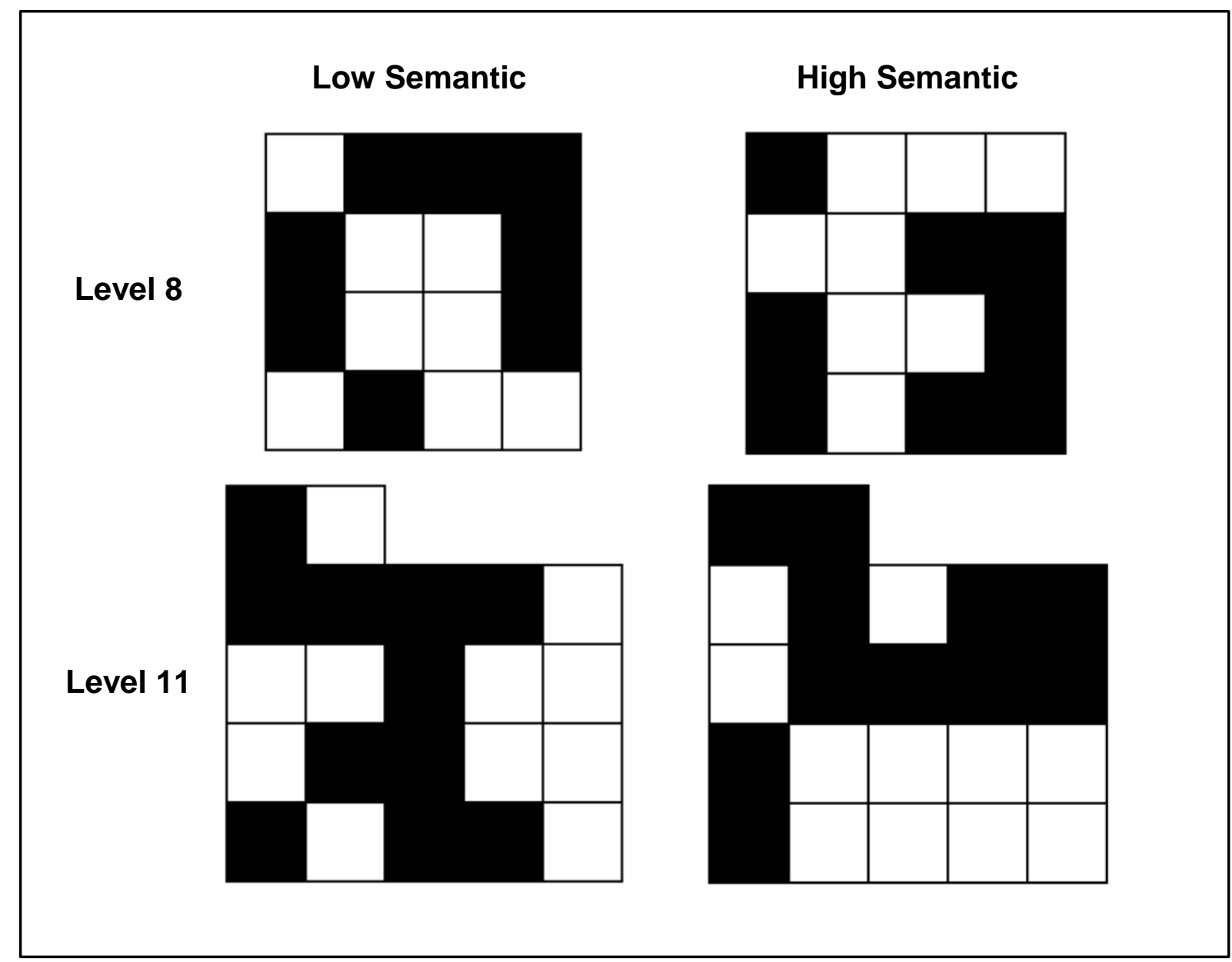

Figure 5: Sample stimuli from the low and high semantic versions of the visual matrix task, at Levels 8 and 11 (Brown et al., 2006; Brown \& Wesley, 2013).

\section{Procedure}

The procedure for Experiment 2 was the same as for the control condition of Experiment 1, with the following exceptions. Participants first completed the ToPF (Pearson, 2009), the duration of which was approximately 5 minutes. Furthermore, both the low and high meaningful versions of the modified Visual Patterns Test were administered to all 
participants, in a counterbalanced fashion across participants. Participants were offered a rest in between performing the two tasks. Once the final task had been administered, all participants were administered the strategy questionnaire, to report their strategic approach during task performance (Appendix 1).

Additionally, for the verbal interference manipulation, half of the participants from each age group were asked to verbalize the first four letters of the alphabet, at a rate of approximately two letters per second (i.e. “A, B, C, D, A, ..”). This was intended to suppress articulation, and was performed throughout encoding, rehearsal, and recall of patterns (as in Brown \& Wesley, 2013). The experimenter carefully monitored articulation throughout each session and recorded articulation rate (number of repetitions per trial). Articulation rates were high in both young $(M=30.10, \mathrm{SD}=3.17)$ and older adults $(M=25.71, S D=3.99)$, although the older adults' articulation rate was significantly smaller, $t(25)=3.15, p=.004$. This can be accounted for by the shorter time taken to recall the smaller patterns that older adults were asked to complete at the outset of each task, as well as the considerably larger patterns that young adults typically recalled towards the end of each task, too.

\section{Results}

The data (see Figure 6) were analyzed using a 2 (age group; young, older) x 2 (verbal interference; control, articulatory suppression) $\times 2$ (task version; low, high meaning) mixed factorial ANOVA. The results showed a significant, marked effect of age group, $F(1,52)=$ $51.13, M S E=6.17, p<.001, \eta_{\mathrm{p}}^{2}=.50\left(M_{\mathrm{YOUNG}}=8.84, S D=1.88 ; M_{\mathrm{OLDER}}=5.48, S D=1.67\right)$, as well as a significant effect of task version, $F(1,52)=6.23, M S E=.968, p=.016, \eta^{2} \mathrm{p}=.11$ $\left(M_{\text {LOW }}=6.93, S D=2.41 ; M_{\text {HIGH }}=7.39, S D=2.67\right)$. The effect of verbal interference did not reach significance, $F(1,52)=3.82, M S E=6.17, p=.056, \eta_{\mathrm{p}}^{2}=.07\left(M_{\mathrm{CONTROL}}=7.62, S D=\right.$ 2.48; $M_{\mathrm{AS}}=6.70, S D=2.38$; as was the case in Brown \& Wesley, 2013). Of greatest importance, however, was the potential for interactions, and the results clearly showed no significant interactions between any of the variables (all other $p>.44$ ). 


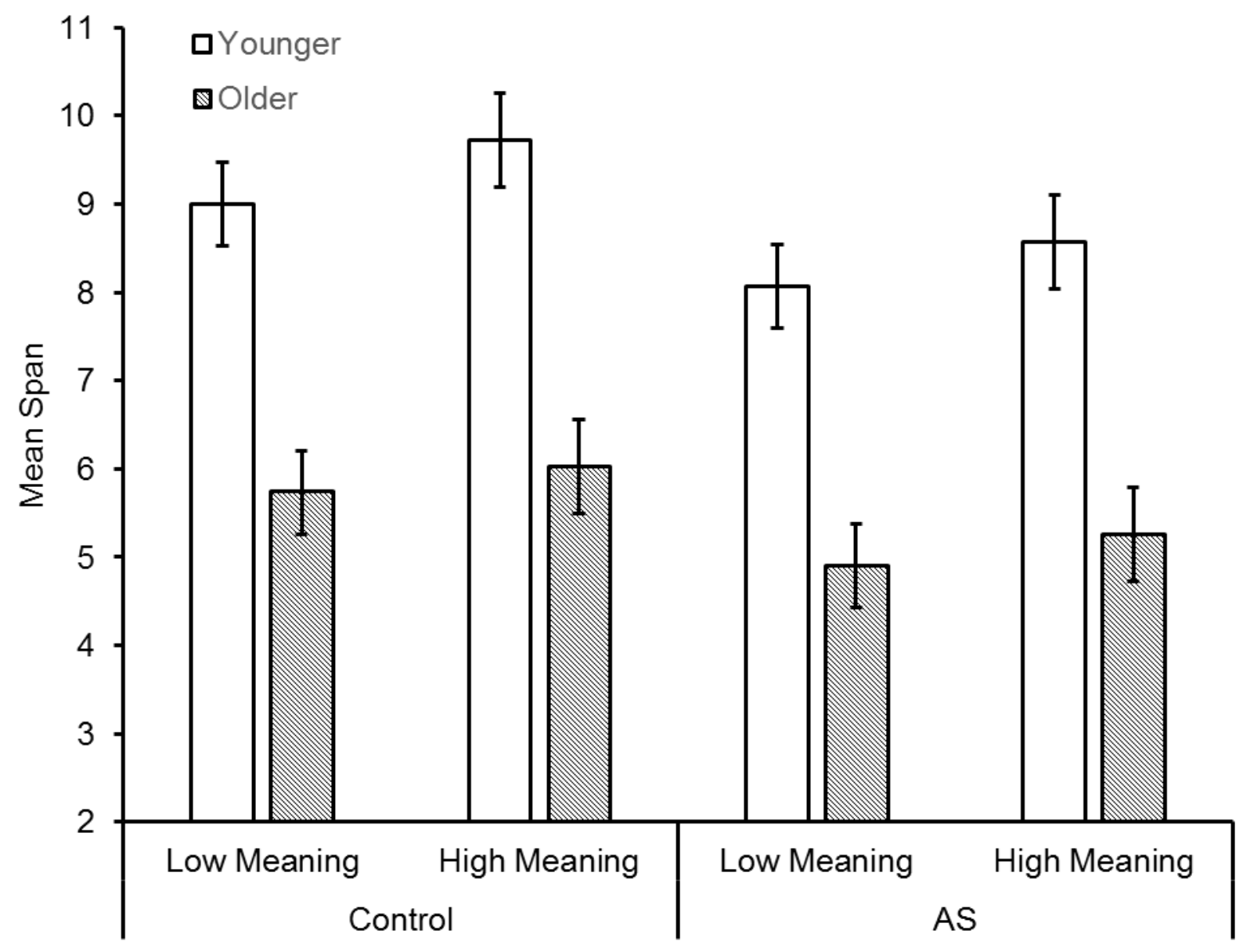

Figure 6: Mean span data ( $\pm \mathrm{SE})$ from Experiment 2, as a function of age group, semantic availability, and articulatory suppression.

Given the importance of administration order in Experiment 1, these data were also analyzed when including this variable in the ANOVA (i.e. low or high semantic task first). This did not influence the pattern of findings detailed above, but there was an additional significant interaction between administration order and task version, $F(1,48)=22.56, M S E=.70, p<$ $.001, \eta^{2} \mathrm{p}=.32$ (see Figure 7). This interaction was followed up using Bonferroni-corrected paired t-tests, to assess the effect of semantics within each administration order. In those carrying out the low semantic task first, there was a marked benefit of semantics, $t(27)=$ $5.67, p<.001\left(M_{\mathrm{LOW}}=6.63, S D=2.23 ; M_{\mathrm{HIGH}}=7.85, S D=2.59\right)$. However, in those completing the task with meaningful stimuli first, there was no reliable difference, $t(27)=$ $1.32, p=.20\left(M_{\text {LOW }}=7.23, S D=2.49 ; M_{\text {HIGH }}=6.94, S D=2.73\right)$. 


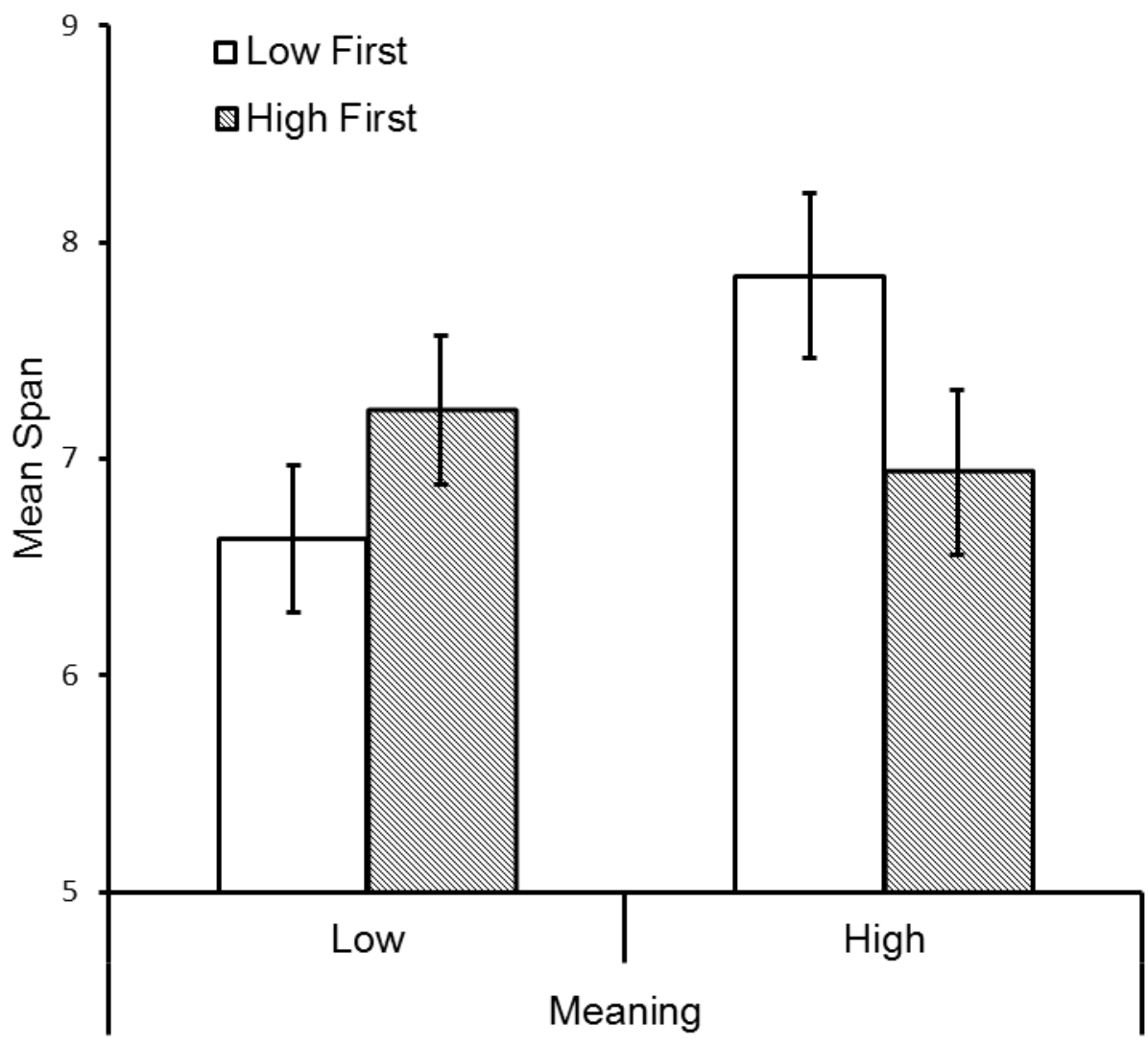

Figure 7: Interaction between stimulus meaning and administration order. Data represent mean span $( \pm \mathrm{SE})$.

Spontaneous strategy use: Strategy questionnaire responses were first analyzed to assess the potential impact of verbal interference (collapsing across age groups), and then of age group (collapsing across verbal interference; see Table 1). 


\section{TABLE 1}

Table 1: Median reported use of each strategy, first by verbal interference condition (collapsed across age group) and then by age group (collapsed across verbal interference). Median values lying between two distinct ratings are hyphenated. See Appendix 1 for full strategy questionnaire.

\begin{tabular}{|c|c|c|c|c|c|c|}
\hline & Control & Verbal Interference & Test Statistics & Young & Older & Test Statistics \\
\hline Rely on verbal-visual strategy & mostly visual & mostly visual & $U=327.00, p=.26$ & equally-mostly visual & mostly visual & $U=278.50, p=.050^{*}$ \\
\hline Combine strategies & mostly & sometimes & $U=265.50, p=.028^{*}$ & sometimes & mostly & $U=345.00, p=.41$ \\
\hline Count up black cells & sometimes & rarely & $U=272.00, p=.045^{\star}$ & rarely & sometimes & $U=266.00, p=.035^{\star}$ \\
\hline Attach verbal labels & mostly & sometimes & $U=318.50, p=.23$ & mostly & sometimes & $U=164.00, p<.001^{* *}$ \\
\hline Refresh mental image & mostly & mostly & $U=317.50, p=.18$ & sometimes & mostly & $U=270.50, p=.030^{*}$ \\
\hline
\end{tabular}

NB: exact significance (2-tailed) $p$-values reported. ${ }^{\star} p<.05 ;{ }^{\star \star} p<.01$. 
Regarding the effect of verbal interference, the median responses reflect a tendency towards a visual strategy in the context of both control and verbal interference conditions, in terms of overall strategy reported (along a verbal-visual continuum), and the extent of mental image refreshing. However, the other three, verbal-related strategies, tend to vary according to verbal interference, in the direction of verbal interference limiting the extent of their use. Mann-Whitney tests revealed that the extent of combining visual and verbal strategies, and 'counting up' cells, were both significantly different across verbal interference conditions. These findings highlight that the articulatory suppression achieved its intended effect of limiting verbalization.

In the analyses of the effect of age group on strategy reports (Table 1), a striking pattern can be observed. Older adults reported relying on visual rehearsal significantly more than young adults, in terms of their overall strategy along the verbal-visual continuum, and regarding mental image refreshing. There was no significant difference between the two age groups regarding the extent of combining visual and verbal strategies. However, for the remaining two, verbal-based, strategies, older adults reported more 'counting up' of cells, whereas the young adults reported more labelling of shapes (i.e. clusters of cells).

Finally, Spearman correlation analyses were carried out to investigate potential relationships between reported strategy use and mean span (collapsed across task version) within each age group, under control conditions. This was to gain insight regarding the extent to which age-related strategy differences actually impacts visual working memory capacity. In young adults, mean span was related to reported strategy use along the verbal-visual continuum, in that incorporating verbalization was related to higher $\operatorname{span}\left(r_{\mathrm{s}}=-.60, p=.023\right.$; all other $p>.10$ ). Interestingly, there was an even split between those who reported verbalizing to some extent (either mostly verbalizing, or using verbal and visual strategies equally) and those who reported mostly or only using a visual strategy (both $n=14$ ). A 2 (task; low, high meaning) x 2 (verbal interference; control, AS) x 2 (strategy; including verbalization or not) mixed ANOVA, performed on the young adult data only, revealed a clear effect of incorporating verbalization on overall capacity, $F(1,24)=11.69, M S E=4.81$, $p=.002, \eta_{\mathrm{p}}^{2}=.33^{3}$. In contrast, in older adults, the extent of mental image refreshing was significantly related to mean span, in the direction that more refreshing was related to a higher mean span $\left(r_{\mathrm{s}}=-.56, p=.038\right.$; all other $\left.p>.22\right)$. Notably, most older people reported

\footnotetext{
${ }^{3}$ The effect of task version noted earlier was still significant $(p=.024)$, and there were no significant interactions (all other $p>.20$ ).
} 
always or mostly refreshing the mental image $(n=20)$, whereas only eight reported using this strategy sometimes or rarely.

\section{Discussion}

The findings from Experiment 2 highlight the benefit of semantic availability (meaning) in this visual working memory task (Brown et al., 2006; Brown \& Wesley, 2013; Hamilton et al., 2018; Orme et al., 2017; Riby \& Orme, 2013). The results replicate those of Brown and Wesley's (2013) investigations in young adults, and support the claim that, in this task, visual semantics is more important to task performance than is active rehearsal in verbal working memory (i.e. sub-vocally repeating verbal labels). However, the present results uniquely show that the pattern of findings is the same in older people; older adults' performance was not impacted any more than that of younger adults by the requirement to perform articulatory suppression. Thus, they do not appear to rely on active verbal rehearsal any more than young people. Furthermore, despite the marked effect of age overall, there was no interaction between age group and task meaning, suggesting that older people benefit from semantic availability to the same extent as young people. This is promising, considering that Hamilton et al., (2018) suggested that older people can relatively automatically gain from visual symmetry, but gain no benefit from semantic availability.

Another important finding was the interaction between semantic availability (task version) and administration order. Regardless of age group, the semantic benefit was more readily capitalized upon after task practice, and the more abstract stimuli were more difficult to recall, even after practice. This pattern therefore further supports the role of task practice identified in the present Experiment 1, and highlights a role for strategy development and implementation over time (Rowe et al., 2008).

Regarding age-related differences in reported spontaneous strategy use, one important finding was that older adults reported relying on visual rehearsal more than young adults, and this was significantly related to capacity in this age group. Additionally, young adults' mixed strategies appear to be more efficient and fit-for-purpose. Although older adults did report typically using a mixed ('combining') approach, they may have done this largely on the basis of counting up pattern cells, rather than more efficiently grouping cells and verbalizing the resulting shapes. Counting up the cells is a time-consuming strategy that does not directly give an indication of the pattern appearance, and may even hinder the ability to encode the whole pattern. In contrast, young adults' reports of labelling pattern shapes would help to 
activate visual semantics and, thus, consolidate shapes (visual appearance) within the patterns.

In summary, there appears to be less variation in strategic approach within older age, with strategy use less flexible and more inefficient, and more limited towards the 'obvious' (visual) strategy. It is important to bear in mind, however, that older adults may report more image refreshing because they are conscious of needing to refresh more explicitly or effortfully. In other words, young adults may be better able to maintain visual images with relatively little effort, allowing the application of executive resources to develop and implement complimentary strategies. Yet another possibility is that the increased reports of image refreshing by older adults could be a by-product of their tendency for greater 'counting up'. This does involve a form of spatial processing that could be perceived and reported as visual refreshing, but is not qualitatively the same as visual refreshing, which focuses upon the visual properties (appearance) of the stimulus.

\section{GENERAL DISCUSSION}

This research was aimed at understanding the working memory mechanisms underlying young and older adults' visual working memory performance, and the roles of multimodal coding and strategy use. Experiment 1 focused upon visual rehearsal, while Experiment 2 assessed verbal rehearsal, as well as visual semantic availability, and self-reported spontaneous strategy use by the two age groups. Both experiments converge upon four main conclusions. First, both young and older adults show evidence of visual rehearsal, but older adults may rely upon this more. Young adults were better able to cope with experiencing visual interference early in the task, perhaps because they are able to more readily develop and/or implement wider strategies. Certainly, there was generally a clear role for the benefit of task practice, also likely related to developing strategies over time. Older adults also reported focusing on visual rehearsal to a greater extent during performance of this visual working memory task. Second, neither age group especially relies upon verbal working memory (i.e. the continued rehearsal of verbal codes) to support performance. Third, in this abstract visual working memory task, both young and older adults benefited from semantic availability (meaning) in the stimuli. Importantly, though, the older people, who exhibited a marked reduction in capacity for recalling abstract visual stimuli from working memory, did not benefit from semantics any more than did young adults. Finally, reported strategy use 
data suggest that young adults employ more verbal-based strategies, and do so more efficiently than older adults. Older adults appear to be less flexible in their strategy use and more fixed on a visual-based approach, perhaps supplemented with more inefficient verbalbased strategies such as 'counting up' the cells. This is contrary to the strategy of labelling collections of cells within patterns, which young people reported employing more than older people, and which is more likely to facilitate the activation of semantic context.

\section{Visuo-spatial and verbal working memory subsystems}

The present findings suggest that both young and older adults employ visual rehearsal (Logie, 2011) while completing this abstract visual working memory task, but that older adults may rely on this even more than young adults. This finding could be due to older adults either being less able to generate or implement other strategies, particularly with minimal task experience, or it could be because they are aware of having to be more effortful with visual refreshing. Both interpretations are plausible. Central executive limitations (Braver \& West, 2008; Reuter-Lorenz, \& Lustig, 2016) could reduce the flexibility of older adults' strategic approach during the task. Equally, though, if visual cortex functioning is susceptible to aging (Davis et al., 2008; Grady et al., 2004), an idea also supported by the marked age-related deficits in visual working memory performance (e.g. Logie \& Maylor, 2009; Murre et al., 2013; Swanson, 2017), then older adults may have to engage in more active visual rehearsal than young adults, supported by anterior, generalized resources (Spreng et al., 2010). Ko et al. (2014; see also Peich et al., 2013) suggested that older adults store a lower quality perceptual trace than young adults, which results in less implicit memory activation when presented with a probe. This relates well to the current notion that, as older adults store a poorer quality representation, they would need to work harder, and possibly differently, to try to keep the trace active and retrievable.

Neither age group appears to rely on active verbal rehearsal for task completion. Based on the strategy report data, however, incorporating verbal-based strategies, such as labelling, helps, and this is likely due to activating semantic context. These findings support those of Brown and Wesley (2013) with young adults, in which articulatory suppression did not interact with stimulus meaning. Verbal rehearsal per se therefore does not account for the benefit observed with the higher meaning stimulus set, and semantic activation (Logie, 2011), and the creation of multimodal codes, likely accounts for the difference. Thus, adopting a flexible strategic approach of combining visual and verbal-based strategies, was shown to 
benefit capacity in the task. This issue is discussed in more detail below. Importantly, though, articulatory suppression was not any more problematic for older adults, emphasising that older adults do not rely on verbal working memory any more than young adults, at least to the extent that it influences recall. Older adults did, however, report more 'counting up' of cells than young adults, a strategy which was more limited with the requirement to engage in articulation. Therefore, although they seem to employ the most fundamentally important strategy of visual rehearsal, and do attempt to incorporate other strategies beyond this, older adults may be more likely than young adults to engage in a relatively inefficient verbal strategy which may not actually increase capacity. Specifically, this verbal strategy does not aid in the recall of visual appearance and could even impede speedy, comprehensive stimulus encoding.

It is important to highlight that processing speed is related to capacity for both visual and verbal active rehearsal. Processing speed has previously been shown to be particularly important in visuo-spatial tasks (Brown et al. 2012, Bopp \& Verhaeghen, 2007; Guest et al. 2015; Jenkins et al. 2000), and an ability that is important in cognitive aging more generally (Salthouse, 1991, 1996; see also Bucur et al., 2008; Deary et al, 2006; Deary, Johnson, \& Starr, 2010). Indeed, Brown et al. (2012) showed that the greatest predictor of older adults' performance of the most abstract version of the present visual working memory task was processing speed. However, visuo-spatial organization (reasoning) was also a unique predictor, with this measure implicating central executive resources for working with visuospatial material. Consequently, processing speed and central executive resources may underlie visual working memory performance in older age, via capacity for encoding information efficiently and appropriately, and engaging in active rehearsal.

\section{Scaffolding by semantic context}

The present research builds upon previous findings to suggest that short-and long-term memory integration benefits visual working memory capacity. Both the present findings, and those of Brown and Wesley (2013), support the notion that it is the semantic difference between the two task versions used in Experiment 2, rather than potential differences in verbal rehearsal, that accounts for the resulting differences in capacity. As articulatory suppression does not remove the benefit of the more meaningful patterns, the findings suggest that semantic codes may be automatically activated and/or strategically created. This would bring context to the otherwise abstract visual patterns (Bower et al., 1975; Delogu, et 
al., 2009; Orme et al., 2017; Postle et al., 2005; Riby \& Orme, 2013; Santa, 1975;

Verhaeghen et al., 2006). However, although semantics may be automatically activated (Brown \& Wesley, 2013; Logie, 2011), this does not necessarily mean that they will be integrated with short-term codes. In fact, multimodal coding does not appear to be cost-free, and may require executive resources, at least for integrating the different codes (Allen et al., 2015; Brown \& Wesley, 2013; Orme et al., 2017). Brown and Wesley showed that, in young adults, neither verbal interference (articulatory suppression) nor spatial interference (spatial tapping) removed the benefit of the high semantic stimuli. However, suppression of the central executive, via the requirement to tap around an array of spatial locations at random time intervals, did so, highlighting the importance of top-down attentional control in the capacity to take advantage of semantic information. Indeed, the present research showed the benefit of task practice (Experiment 1), and specifically that semantics helped more as the task progressed (Experiment 2). This emphasizes a role for strategy development over time (Rowe et al., 2008).

A key aim for the present research was to assess whether or not older adults could differentially benefit from the more meaningful stimuli, given the relative age-related decrement in performance levels with more abstract patterns. Under the present conditions, older adults do not appear able to compensate for their reduced visual working memory capacity by incorporating more generalized resources, specifically, capitalising upon visual semantics (Mayr \& Kliegl, 2000). While they were able to benefit to the same extent as young adults in the present Experiment 2, the gap in performance was not reduced by semantic availability. In fact, recent research has resulted in even less promising findings than this. Also using a visual matrix task to measure visual working memory, Hamilton et al. (2018) showed that older adults actually benefitted less than young adults from semantic availability. It is possible that the slightly greater task practice included in the present study could have influenced the presently observed benefit of meaning in the older adults (i.e. by starting older adults at level 2, task practice would have been more even across age groups; Rowe et al., 2008). Alternatively, the specific stimulus sets used across the two studies may have been important to whether or not older adults were able to benefit from meaning. One final key difference between the two paradigms is that Hamilton et al. used a very brief $(1 \mathrm{~s})$ maintenance interval, whereas presently there was a delay period of $10 \mathrm{~s}$ within each trial. It is possible that longer delay periods allow older adults to take advantage of semantic availability, by allowing more time to identify and/or implement the strategy (Brown et al., 2012; Salthouse, 1996). The two studies, however, do converge on the conclusion that older 
adults, under the circumstances already investigated, do not benefit any more than young adults, and therefor do not show evidence of compensation to the extent of reducing the agerelated deficit. Interestingly, in a neuroimaging analysis of older adults' encoding of different categories of visual objects, Carp et al. (2011) not only showed less neural distinctiveness in ventral visual cortex, but found no evidence that this reduced specificity was compensated for by neural resources either within or beyond visual cortex. Notably, Hamilton et al. did find that perceptual affordance (i.e. availability of symmetry) could be used by older adults to boost performance, and this may have been a more automatic process than using visual semantics (Mayr \& Kliegl, 2000).

Nevertheless, this conclusion does not necessarily mean that compensation is impossible in older adults' visual working memory. The present task involved encoding, maintaining, and recalling abstract visual patterns, and even the higher semantic task version was still relatively abstract. Therefore, increasing the concreteness even further may perhaps show a differential benefit for older people. Also, given the suggestion from Experiment 1, that strategies develop over time, the older adults may have benefited more if they had gained even more task practice (Rowe et al., 2008). In the context of working memory performance, Carp et al. (2010) provided neural evidence for compensation during maintenance, but they showed that memory load was crucial, in that compensation was achievable by older adults only at lower loads (see also Reuter-Lorenz \& Cappell, 2008; Reuter-Lorenz \& Lustig, 2016). Therefore, future analyses should take task level (load) into account. Finally, the present study focused upon spontaneous strategy use and the researchers specifically did not mention strategic approach or the availability of semantics until after the task was completed. Thus, it may be the case that strategy instruction would be needed to observe differential benefits that could reduce the age-related deficit in this task (Cherry, Park, Frieske, \& Smith, 1996; see also Reuter-Lorenz \& Park, 2014). In other words, the requirement for self-initiated processing may interact with the availability of environmental support, such as semantic context (e.g. Mayr \& Kliegl, 2000; Smith et al. 1998). Overall, frontal resources for strategy use may be implicated in the extent to which older adults are able to develop and/or implement compensatory processing (Reuter-Lorenz, \& Lustig, 2005). Future research may usefully explore these issues to develop understanding of older adults' potential to benefit from multimodal coding in a visual working memory task. 


\section{Strategic approach}

Another specific focus of the present research was upon establishing the strategies spontaneously used by older adults, relative to young adults. Importantly, it is not always the case that strategy use differs between young and older adults. For example, in a study of probabilistic category learning, Fera et al. (2005) showed that, despite differential neural activation patterns, both age groups displayed similar learning curves and the same reported strategies. Yet, Lemaire (2016) noted that, where age-related deficits are observed in cognitive performance, it is likely that strategy differences are also observed. Indeed, in a verbal paired-associates task, for example, in which older adults are typically poorer than young adults, Tournier and Postal (2011) showed that older adults used a sentence strategy more readily than an imagery one, and were less strategically adaptive than young adults.

In the present research, older adults exhibited consistently lower capacities than young adults and, in parallel, also reported less efficient strategy use. To summarize the strategy use findings, older adults reported adopting more active visual rehearsal, more 'counting up' of pattern cells, and less labelling of collective shapes within patterns. Previously, age-related differences in strategy selection have been accounted for, at least in part, by executive functioning (e.g. Hodzik \& Lemaire, 2011; Bouazzaoui et al., 2010). Older adults appear to switch strategies less frequently than young adults, and this is exacerbated in more difficult tasks (Ardiale \& Lemaire, 2012, 2013). Spreng et al. (2010) showed that older adults need frontal cortex resources sooner than young adults, but that young adults can activate these resources to a greater extent, when a task is more difficult. It is entirely possible that older adults employ different, but perhaps less efficient, strategies at lower task loads, and then under-activate neural resources at higher levels, due to excessive demand. That is, their strategies may no longer be appropriate at higher levels (e.g. Reuter-Lorenz \& Lustig, 2016). This account maps well onto the present 'counting up' strategy, which may be somewhat useful at lower levels of the task where, for example, this strategy may happen to encourage active visuo-spatial rehearsal (Logie, 2011). However, at higher task levels, where more information must be encoded within the same limited time, this is no longer practicable. Simultaneously, central executive limitations would bring a difficulty in establishing new, more efficient strategies. Thus, central executive resources (along with processing speed; Salthouse, 1996) may be implicated in the age-related decline in visual working memory performance (Brown et al., 2012). However, the findings directly implicate a role for strategy. Given the observed age-related inefficiency in strategic approach, a natural question 
stemming from the present research is whether or not older adults' working memory performance could be enhanced through strategy training (e.g. Bailey et al., 2014; Logie, 2012). This seems possible, particularly if the training included emphasizing the efficient as well as the inefficient strategies, so that efficient ones are preferable from the outset of the task.

While the present work has established some important findings for older adults' spontaneous strategy use in visual working memory, more research is now required to understand the complexities in young and older adults' knowledge and implementation of strategies in visual working memory. Using Lemaire's (2010; see also Lemaire \& Siegler, 1995 ) conceptual model of strategy variation, the present work has identified a difference in the strategy repertoire of older versus young adults. However, there may also be differences in the distribution, execution, and/or selection of strategies, and this will be important for determining the target areas for future training studies. For example, it will be important to determine how strategy use may vary during task completion, both in terms of task practice, and task level (difficulty). Participants could also be asked to describe their strategies for themselves, allowing more insight around the extent of available strategies in visual working memory. In the present research, in order not to influence meta-cognition around strategy use, the strategy questionnaire was specifically administered after testing visual working memory. Particularly now that spontaneous, unbiased strategy use has been measured, future research could assess strategy use throughout task performance, such as trial-by-trial, yielding more insight around variation in strategy use across time (i.e. strategy distribution) and data such as percentage strategy use across age groups (Lemaire, 2016). This approach would also be amenable to assessing the impact of strategy instructions, and how this might vary with aging (e.g. Atkinson, Baddeley, \& Allen, 2017), and would be particularly interesting given the importance of task practice reported presently.

\section{Conclusions}

The present research serves as a foundation for our understanding the role of working memory mechanisms, strategic approach, and multimodal coding in young and older adults' visual working memory performance. In addition to supporting previous evidence of marked age-related deficits in visual working memory, and the general benefit of visual semantics, the key unique findings are that both young and older adults use visual rehearsal, combined with some form of verbal-based approach. However, older adults appear to rely upon visual 
rehearsal to a greater extent than young adults, who use more efficient verbal-based strategies such as labelling pattern configurations. Such a strategy can aid later recall of visual appearance, on the basis of the associated visual semantics. In contrast, older adults report more use of an inefficient 'counting up' strategy, which does not benefit later visual recall, especially at larger stimulus sizes, and could even hinder the encoding process. Although there was no differential benefit of the availability of semantics for older adults, these findings show promise, as there is now clear scope to train older adults on the range of available strategies in this visual working memory task. Indeed, the current research contributes valuable evidence to the developing literature on the broader role of strategy in cognitive aging (Nyberg et al., 2003). This is particularly important in the context of population aging, and the range of findings highlighting the potential benefits of cognitive training, both in healthy aging (e.g. Buschkuehl et al., 2008; Hastings \& West, 2009; Willis et al., 2006; for meta-analyses, see Karbach \& Verhaeghen, 2014; Kelly et al., 2014) and for reducing dementia risk (Edwards et al., 2017). Taking strategy into account, along with task practice, may help to maximize the benefits of training. Overall, the present findings suggests that the age-related deficit in visual working memory performance may be caused, at least in part, by two interactive processes, specifically a difficulty storing visual representations, along with changes in strategic approach. It is hoped that these findings will now stimulate future research addressing age-related declines in visual working memory, with a view to identifying methods for improving older adults' capacity.

\section{REFERENCES}

Allen, R. J., Havelka, J., Falcon, T., Evans, S., \& Darling, S. (2015). Modality specificity and integration in working memory: insights from visuospatial bootstrapping. Journal of Experimental Psychology: Learning, Memory, and Cognition, 41, 820-830. doi: 10.1037/xlm0000058

Ardiale, E., \& Lemaire, P. (2012). Within-item strategy switching: An age comparative study in adults. Psychology and Aging, 27, 1138-1151. doi: 10.1037/a0027772

Ardiale, E., \& Lemaire, P. (2013). Effects of execution duration on within-item strategy switching in young and older adults. Journal of Cognitive Psychology, 25, 464-472. doi: $10.1080 / 20445911.2013 .789854$ 
Atkinson, A. L., Baddeley, A. D., \& Allen, R. J. (2017): Remember some or remember all? Ageing and strategy effects in visual working memory. The Quarterly Journal of Experimental Psychology. doi: 10.1080/17470218.2017.1341537

Baddeley, A. D. (2007). Working memory, Thought and Action. Oxford, UK: Oxford University Press.

Bailey, H., Dunlosky, J., \& Hertzog, C. (2009). Does differential strategy use account for agerelated deficits in working-memory performance? Psychology and Aging, 24, 82-92. doi: $10.1037 / \mathrm{a} 0014078$

Bailey, H., R., Dunlosky, J., \& Hertzog, C. (2014). Does strategy training reduce age-related deficits in working memory? Gerontology, 60. 346-356. doi: 10.1159/000356699

Beigneux, K., Plaie, T., \& Isingrini, M. (2007). Aging effects on visual and spatial components of working memory. International Journal of Aging and Human Development, 65, 301314. doi: 10.2190/AG.65.4.b

Bopp, K. L., \& Verhaeghen, P. (2005). Aging and verbal memory span: A meta-analysis. Journals of Gerontology Series B: Psychological Sciences \& Social Sciences, 60, 223233. doi: 10.1093/geronb/60.5.P223

Bopp, K. L., \& Verhaeghen, P. (2007). Age-related differences in control processes in verbal and visuospatial working memory: Storage, transformation, supervision, and coordination. Journals of Gerontology Series B: Psychological Sciences \& Social Sciences, 62, 239-246. doi: 10.1093/geronb/62.5.P239

Borst, G., Ganis, G., Thompson, W. L., \& Kosslyn, S. M. (2012). Representations in mental imagery and working memory: Evidence from different types of visual masks. Memory \& Cognition, 40, 204-217. doi: 10.3758/s13421-011-0143-7

Bouazzaoui, B., Isingrini, M., Fay, S., Angel, L., Vanneste, S., Clarys, D., \& Taconnat, L. (2010). Aging and self-reported internal and external memory strategy uses: The role of executive functioning. Acta Psychologica, 135, 59-66. doi: 10.1016/j.actpsy.2010.05.007.

Bower, G. H. (1970). Analysis of a mnemonic device. American Scientist, 58, 496-510.

Bower, G. H., Karlin, M. B. \& Dueck, A. (1975). Comprehension and memory for pictures. Memory \& Cognition, 3, 216-220. doi: 10.3758/BF03212900

Brandimonte, M. A., Hitch, G. J., \& Bishop, D. V. (1992a). Influence of short-term memory codes on visual image processing: Evidence from image transformation tasks. Journal of Experimental Psychology: Learning, Memory, and Cognition, 18, 157-165. doi: 10.1037/0278-7393.18.1.157 
Brandimonte, M. A., Hitch, G. J. \& Bishop, D. V. M. (1992b). Verbal recoding of visual stimuli impairs mental image transformations. Memory \& Cognition, 20, 449-455. doi: 10.3758/BF03210929

Braver, T. S., \& West, R. L. (2008). Working memory, executive control, and aging. In F. I. M. Craik \& T. A. Salthouse (Eds.), The Handbook of Aging and Cognition (3rd Ed.), pp. 311-372. New York: Psychology Press.

Brown, L. A. (2016). Spatial-sequential working memory in younger and older adults: age predicts backward recall performance within both age groups. Frontiers in Psychology, 7:1514. doi: 10.3389/fpsyg.2016.01514

Brown, L. A., Brockmole, J. R., Gow, A. J., \& Deary, I. J. (2012). Processing speed and visuospatial executive function predict visual working memory ability in older adults. Experimental Aging Research, 38, 1-19. doi: 10.1080/0361073X.2012.636722

Brown, L. A., Forbes, D., \& McConnell, J. (2006). Limiting the use of verbal coding in the Visual Patterns Test. Quarterly Journal of Experimental Psychology, 59, 1169-1176. doi: $10.1080 / 17470210600665954$

Brown, L. A., \& Wesley, R. (2013). Visual working memory is enhanced by mixed strategy use and semantic coding. Journal of Cognitive Psychology, 25, 328-338. doi: 10.1080/20445911.2013.773004

Bruyer, R., \& Scailquin, J. C. (1999). Assessment of visuo-spatial short-term memory and effect of aging. European Review of Applied Psychology, 49, 175-181.

Bucur, B., Madden, D. J., Spaniol, J., Provenzale, J. M., Cabeza, R., White, L. E., \& Huettel, S. A. (2008). Age-related slowing of memory retrieval: Contributions of perceptual speed and cerebral white matter integrity. Neurobiology of Aging, 29, 1070-1079. doi: 10.1016/j.neurobiolaging.2007.02.008

Burianová, H., Lee, Y., Grady, C. L., \& Moscovitch, M. (2013). Age-related dedifferentiation and compensatory changes in the functional network underlying face processing, Neurobiology of Aging, 34, 2759-2767. doi: 10.1016/j.neurobiolaging.2013.06.016.

Cabeza, R., Anderson, N. D., Locantore, J. K., \& McIntosh, A. R. (2002). Aging gracefully: Compensatory brain activity in high-performing older adults. NeuroImage, 17, 13941402. doi:10.1006/nimg.2002.1280

Campoy, G., Castellà, J., Provencio, V., Hitch, G. J., \& Baddeley, A. D. (2015). Automatic semantic encoding in verbal short-term memory: Evidence from the concreteness effect. The Quarterly Journal of Experimental Psychology, 68, 759-778. doi: $10.1080 / 17470218.2014 .966248$ 
Carp, J., Gmeindl, L., \& Reuter-Lorenz, P. A. (2010). Age differences in the neural representation of working memory revealed by multi-voxel pattern analysis. Frontiers in Human Neuroscience, 4, 217. doi: 10.3389/fnhum.2010.00217

Carp, J., Park, J., Polk, T. A., \& Park, D. C (2011) Age differences in neural distinctiveness revealed by multi-voxel pattern analysis. NeuroImage, 56, 736-743. doi: 10.1016/j.neuroimage.2010.04.267

Cherry, K. E., Park, D. C., Frieske, D. A., \& Smith, A. D. (1996). Verbal and pictorial elaborations enhance memory in younger and older adults. Aging, Neuropsychology, and Cognition, 3, 15-29. doi: 10.1080/13825589608256609

Darling, S., Della Sala, S., \& Logie, R. H. (2009) Dissociation between appearance and location within visuo-spatial working memory. Quarterly Journal of Experimental Psychology, 62, 417-425. doi: 10.1080/17470210802321984

Davis, S. W., Dennis, N. A., Daselaar, S. M., Fleck, M. S., Cabeza, R. (2008). Qué PASA? The Posterior-Anterior Shift in Aging. Cerebral Cortex, 18, 1201-1209. doi: 10.1093/cercor/bhm155

Dean, G. M., Dewhurst, S. A., Morris, P. E., \& Whittaker, A. (2005). Selective interference with the use of visual images in the symbolic distance paradigm. Journal of Experimental Psychology: Learning, Memory, and Cognition, 31, 1043-1068. doi: 10.1037/02787393.31.5.1043

Dean, G. M., Dewhurst, S. A., Whittaker, A. (2008). Dynamic visual noise interferes with storage in visual working memory. Experimental Psychology, 55, 283-289. doi: 10.1027/1618-3169.55.4.283

Deary, I. J., Bastin, M. E., Pattie, A., Clayden, J. D., Whalley, L. J., Starr, J. M., et al. (2006). White matter integrity and cognition in childhood and old age. Neurology, 66, 505-512. doi: 10.1212/01.wnl.0000199954.81900.e2

Deary, I. J., Johnson, W., \& Starr, J. M. (2010). Are processing speed tasks biomarkers of cognitive aging? Psychology and Aging, 25, 219-228. doi: 10.1037/a0017750

Della Sala, S., Gray, C., Baddeley, A., Allamano, N., \& Wilson, L. (1999). Pattern span: A tool for unwelding visuo-spatial memory. Neuropsychologia, 37, 1189-1199. doi: 10.1016/S0028-3932(98)00159-6

Della Sala, S., Gray, C., Baddeley, A., \& Wilson, L. (1997). Visual patterns test: a test of shortterm visual recall. Bury St Edmunds, UK: Thames Valley Test Company. 
Delogu, F., Raffone, A., \& Belardinelli, M. O. (2009) Semantic encoding in working memory: Is there a (multi)modality effect? Memory, 17, 655-663. doi: $10.1080 / 09658210902998054$

de Ribaupierre, A., Lecerf, T., \& Bailleux, C. (2000). Is a nonverbal working memory task necessarily nonverbally encoded? Current Psychology of Cognition, 19, 135-170.

Duverne, S., \& Lemaire, P. (2004). Age-related differences in arithmetic problem-verification strategies. The Journals of Gerontology: Series B, 59, P135-P142. doi: 10.1093/geronb/59.3.P135

Edwards, J. D., Xu, H., Clark, D. O., Guey, L. T., Ross, L. A., \& Unverzagt, F. W. (2017). Speed of processing training results in lower risk of dementia. Alzheimer's \& Dementia: Translational Research \& Clinical Interventions, 3, 603-611. doi: 10.1016/j.trci.2017.09.002

Fera, F., Weickert, T. W., Goldberg, T. E., Tessitore, A., Hariri, A., Das, S., ... Mattay, V. S. (2005). Neural mechanisms underlying probabilistic category learning in normal aging. Journal of Neuroscience, 25, 11340-11348. doi: 10.1523/JNEUROSCI.2736-05.2005

Fiore, F., Borella, E., Mammarella, I. C., \& De Beni, R. (2012). Age differences in verbal and visuo-spatial working memory updating: Evidence from analysis of serial position curves. Memory, 20, 14-27. doi: 10.1080/09658211.2011.628320

Folstein, M. F., Folstein, S. E., \& McHugh, P. R. (1975). "Mini-Mental State”: A practical method for grading the cognitive state of patients for the clinician. Journal of Psychiatric Research, 12, 189-198. doi: 10.1016/0022-3956(75)90026-6

Geerligs, L., Maurits, N. M., Renken, R. J. \& Lorist, M. M. (2014). Reduced specificity of functional connectivity in the aging brain during task performance. Human Brain Mapping, 35, 319-330. doi: 10.1002/hbm.22175

Grady, C. L. (1996). Age-related changes in cortical blood flow activation during perception and memory. Annals of the New York Academy of Sciences, 777, 14-21. doi:10.1111/j.1749-6632.1996.tb34396.x

Grady, C. L., Maisog, J. M., Horwitz, B., Ungerleider, L. G., Mentis, M. J., Salerno, J. A., ... Haxby, J. V. (1994). Age-related changes in cortical blood flow activation during visual processing of faces and location. Journal of Neuroscience 14, 1450-1462.

Guest, D., Howard, C., Brown, L. A., \& Gleeson, H. (2015). Aging and the rate of visual information processing. Journal of Vision, 15:10, 1-25. doi: 10.1167/15.14.10 
Jenkins, L., Myerson, J., Joerding, J. A., \& Hale, S. (2000). Converging evidence that visuospatial cognition is more age-sensitive than verbal cognition. Psychology and Aging, 15, 157-175. doi: 10.1037/0882-7974.15.1.157

Johnson, W., Logie, R. H., \& Brockmole, J. R. (2010). Working memory tasks differ in factor structure across age cohorts: Implications for dedifferentiation. Intelligence, 38, 513528. doi: 10.1016/j.intell.2010.06.005.

Hamilton, C. J., Brown, L. A., \& Rossi-Arnaud, C. (2018). Older adults benefit from symmetry, but not semantic availability, in visual working memory. Frontiers in Psychology, 8:2373. doi: 10.3389/fpsyg.2017.02373

Hastings, E. C., \& West, R. L. (2009). The relative success of a self-help and a group-based memory training program for older adults. Psychology and Aging, 24, 586-594. doi: $10.1037 / \mathrm{a} 0016951$

Hedden, T., \& Gabrieli, J. D. E. (2004). Insights into the ageing mind: a view from cognitive neuroscience. Nature Reviews Neuroscience, 5, 87-96. doi: 10.1038/nrn1323

Hinault, T., Lemaire, P., \& Touron, D. (2017). Aging effects in sequential modulations of poorer-strategy effects during execution of memory strategies. Memory, 25, 176-186. doi: 10.1080/09658211.2016.1146300

Hodzik, S., \& Lemaire, P. (2011). Inhibition and shifting capacities mediate adults' agerelated differences in strategy selection and repertoire. Acta Psychologica, 137, 335344. doi: 10.1016/j.actpsy.2011.04.002

Karbach, J., \& Verhaeghen, P. (2014). Making working memory work: a meta-analysis of executive-control and working memory training in older adults. Psychological Science, 25, 2027-2037. doi: 10.1177/0956797614548725

Kelly, M. E., Loughrey, D., Lawlor, B. A., Robertson, I. H., Walsh, C., \& Brennan, S. (2014). The impact of cognitive training and mental stimulation on cognitive and everyday functioning of healthy older adults: A systematic review and meta-analysis. Ageing Research Reviews, 15, 28-43. doi: 10.1016/j.arr.2014.02.004

Kliegl, R., Mayr, U., \& Krampe, R. T. (1994). Time-accuracy functions for determining process and person differences: an application to cognitive aging. Cognitive Psychology 26, 134-164. doi: 10.1006/cogp.1994.1005

Ko, P. C., Duda, B., Hussey, E., Mason, E., Molitor, R. J., Woodman, G. F., \& Ally, B. A., (2014). Understanding age-related reductions in visual working memory capacity: Examining the stages of change detection. Attention, Perception, \& Psychophysics, 76, 2015-2030. doi: 10.3758/s13414-013-0585-Z 
Kuhlmann, B. G., \& Touron, D. R. (2012). Mediator-based encoding strategies in source monitoring in young and older adults. Journal of Experimental Psychology: Learning, Memory, and Cognition, 38, 1352-1364. doi: 10.1037/a0027863

Larsen, J. D., \& Baddeley, A. (2003). Disruption of verbal STM by irrelevant speech, articulatory suppression, and manual tapping: Do they have a common source? The Quarterly Journal of Experimental Psychology, 56, 1249-1268. doi: $10.1080 / 02724980244000765$

Lemaire, P. (2016). Cognitive aging: The role of strategies. New York, NY; Routledge. Lemaire, P., \& Siegler, R. S. (1995). Four aspects of strategic change: Contributions to children's learning of multiplication. Journal of Experimental Psychology: General, 124, 83-97. doi: 10.1037/0096-3445.124.1.83

Leonards, U., Ibanez, V., \& Giannakopoulos, P. (2002). The role of stimulus type in agerelated changes of visual working memory. Experimental Brain Research, 146, 172183. doi: $10.1007 / \mathrm{s} 00221-002-1175-9$

Li, S.-C., Lindenberger, U., Sikström, S. (2001). Aging cognition: from neuromodulation to representation. Trends in Cognitive Sciences, 5, 479-486. doi: 10.1016/S13646613(00)01769-1.

Li, S.-C., \& Sikström, S. (2002). Integrative neurocomputational perspectives on cognitive aging, neuromodulation, and representation. Neuroscience \& Biobehavioral Reviews, 26, 795-808. doi: 10.1016/S0149-7634(02)00066-0

Logie, R. H. (2011). The functional organization and capacity limits of working memory. Current Directions in Psychological Science, 20, 240-245. doi: $10.1177 / 0963721411415340$

Logie, R. H. (2012). Cognitive training: Strategies and the multicomponent cognitive system. Journal of Applied Research in Memory and Cognition, 1, 206-207. doi: 10.1016/j.jarmac.2012.07.006

Logie, R. H., Della Sala, S., Laiacona, M., Chalmers, P., \& Wynn, V. (1996). Group aggregates and individual reliability: The case of verbal short-term memory. Memory \& Cognition, 24, 305-321. doi: 10.3758/BF03213295

Logie, R. H., \& Maylor, E. A. (2009). An internet study of prospective memory across adulthood. Psychology and Aging, 24, 767-774. doi: 10.1037/a0015479

Luck, S. J., \& Vogel, E. K. (2013). Visual working memory capacity: from psychophysics and neurobiology to individual differences. Trends in Cognitive Sciences, 17, 391-400. doi: 10.1016/j.tics.2013.06.006 
Ma, W. J., Husain, M., \& Bays, P. M. (2014). Changing concepts of working memory. Nature Neuroscience, 17, 347-356. doi: 10.1038/nn.3655

Mammarella, I. C., Giofrè, D., Caviola, S., Cornoldi, C., \& Hamilton, C. (2014). Visuospatial working memory in children with autism: The effect of a semantic global organization. Research in Developmental Disabilities, 35, 1349-1356. doi:

10.1016/j.ridd.2014.03.030

Mayr, U., \& Kliegl, R. (2000). Complex semantic processing in old age: does it stay or does it go? Psychology and Aging, 15, 29-43. doi: 10.1037//0882-7974.15.1.29

McConnell, J., \& Quinn, J. G. (2000). Interference in visual working memory. Quarterly Journal of Experimental Psychology, 53A, 53-67. doi: 10.1080/713755873

McConnell, J., \& Quinn, J. G. (2004). Complexity factors in visuo-spatial working memory. Memory, 12, 338-350. doi: 10.1080/09658210344000035

Murre, J. M. N., Janssen, S. M. J., Rouw, R., \& Meeter, M. (2013). The rise and fall of immediate and delayed memory for verbal and visuospatial information from late childhood to late adulthood. Acta Psychologica, 142, 96-107. doi: 10.1016/j.actpsy.2012.10.005.

Myerson, J., Hale, S., Rhee, S. H., \& Jenkins, L. (1999). Selective interference with verbal and spatial working memory in young and older adults. Journals of Gerontology Series B: Psychological Sciences \& Social Sciences, 54, 161-164. doi: 10.1093/geronb/54B.3.P161

Naveh-Benjamin, M., Brav, T. K., \& Levy, O. (2007). The associative memory deficit of older adults: The role of strategy utilization. Psychology and Aging, 22, 202-208. doi: $10.1037 / 0882-7974.22 .1 .202$

Noack, H., Lövdén, M., \& Lindenberger, U. (2012). Normal aging increases discriminal dispersion in visuospatial short-term memory. Psychology and Aging, 27, 627-637. doi: $10.1037 / \mathrm{a} 0027251$

Nyberg, L., Sandblom, J., Jones, S., Neely, A. S., Petersson, K. M., Ingvar, M., \& Bäckman, L. (2003). Neural correlates of training-related memory improvement in adulthood and aging. Proceedings of the National Academy of Sciences of the United States of America, 100, 13728-13733. doi: 10.1073/pnas.1735487100

Orme, E., Brown, L. A., \& Riby, L. M. (2017). Retrieval and monitoring processes during visual working memory: An ERP study of the benefit of visual semantics. Frontiers in Psychology, 8:1080. doi: 10.3389/fpsyg.2017.01080

Paivio, A. (1971). Imagery and verbal processes. New York: Holt, Rinehart and Winston. 
Paivio, A. (1991). Images in Mind: The Evolution of a Theory. Hertfordshire: Harvester Wheatsheaf.

Park, J., Carp, J., Hebrank, A., Park, D. C., \& Polk, T. A. (2010). Neural specificity predicts fluid processing ability in older adults. Journal of Neuroscience, 30, 9253-9259. doi: 10.1523/JNEUROSCI.0853-10.2010

Park, J., Carp, J., Kennedy, K. M., Rodrigue, K. M., G. N., Bischof, G. N., Huang, C.-M., ... Park, D. C. (2012). Neural broadening or neural attenuation? Investigating age-related dedifferentiation in the face network in a large lifespan sample. Journal of Neuroscience, 32, 2154-2158. doi: 10.1523/JNEUROSCI.4494-11.2012

Park, C., Lautenschlager, G., Hedden, T., Davidson, N. S., Smith, A. D. \& Smith, P. K. (2002) Models of visuospatial and verbal memory across the adult life span. Psychology and Aging, 17, 299-320. doi: 10.1037/0882-7974.17.2.299

Park, D. C., Polk ,T. A., Park, R., Minear, M., Savage, A., \& Smith, M. R. (2004). Aging reduces neural specialization in ventral visual cortex. Proceedings of the National Academy of Sciences of the United States of America, 101, 13091-13095. doi: 10.1073/pnas.0405148101

Park, D. C., \& Reuter-Lorenz, P. (2009). The adaptive brain: Aging and neurocognitive scaffolding. Annual Review of Psychology, 60, 173-196. doi: 10.1146/annurev.psych.59.103006.093656

Payer, D., Marshuetz, C., Sutton, B., Hebrank, A., Welsh, R. C., \& Park, D. C. (2006). Decreased neural specialization in old adults on a working memory task. Neuroreport, 17, 487-491. doi: 10.1097/01.wnr.0000209005.40481.31

Pearson Education, Inc. (2009). Test of Premorbid Functioning - UK Edition. London; Pearson Assessment.

Peich, M., Husain, M., \& Bays, P. M. (2013). Age-related decline of precision and binding in visual working memory. Psychology and Aging, 28, 729-743. doi: 10.1037/a0033236

Postle, B. R., D’Esposito, M., \& Corkin, S. (2005). Effects of verbal and nonverbal interference on spatial and object visual working memory. Memory \& Cognition, 33, 203-212. doi: 10.3758/BF03195309

Postle, B. R., \& Hamidi, M. (2007). Nonvisual codes and nonvisual brain areas support visual working memory. Cerebral Cortex, 17, 2151-2162. doi: 10.1093/cercor/bhl123

Quinn, J. G., \& McConnell, J. (1996a). Irrelevant pictures in visual working memory. Quarterly Journal of Experimental Psychology, 49A, 200-215. doi: 10.1080/713755613 
Quinn, J. G., \& McConnell, J. (1996b). Indications of the functional distinction between the components of visual working memory. Psychologische Beitrage, 38, 355-367.

Reuter-Lorenz, P. A., \& Cappell, K. A. (2008). Neurocognitive aging and the compensation hypothesis. Current Directions in Psychological Science, 17, 177- 182. doi: 10.1111/j.1467-8721.2008.00570.x

Reuter-Lorenz, P. A., \& Lustig, C. (2005). Brain aging: reorganizing discoveries about the aging mind. Current Opinion in Neurobiology, 15, 245-251. doi: 10.1016/j.conb.2005.03.016

Reuter-Lorenz, P. A., \& Lustig, C. (2016). Working memory and executive functions in the aging brain. In R. Cabeza, L. Nyberg, and D. C. Park (Eds.), Cognitive neuroscience of aging: Linking cognitive and cerebral aging ( $2^{\text {nd }}$ Ed.). New York, NY: Oxford University Press. doi: 10.1093/acprof:oso/9780199372935.003.0010

Reuter-Lorenz, P. A., \& Park, D. C. (2010). Human neuroscience and the aging mind: a new look at old problems. Journal of Gerontology: Psychological Sciences, 65B, 405-415. doi: 10.1093/geronb/gbq035

Reuter-Lorenz, P. A., \& Park, D. C. (2014). How does it STAC up? Revisiting the Scaffolding Theory of Aging and Cognition. Neuropsychology Review, 24, 355-370. doi: 10.1007/s11065-014-9270-9

Riby, L. M., \& Orme, E. (2013). A familiar pattern? Semantic memory contributes to the enhancement of visuo-spatial memories. Brain and cognition, 81, 215-222. doi: 10.1016/j.bandc.2012.10.011

Rowe, G., Hasher, L., \& Turcotte, J. (2008). Age differences in visuospatial working memory. Psychology and Aging, 23, 79-84. doi: 10.1037/0882-7974.23.1.79

Salthouse, T. A. (1991). Mediation of adult age differences in cognition by reductions in working memory and speed of processing. Psychological Science, 2, 179-183. doi: 10.1111/j.1467-9280.1991.tb00127.x

Salthouse, T. A. (1996). The processing-speed theory of adult age differences in cognition. Psychological Review, 103, 403-428. doi: 10.1037/0033-295X.103.3.403

Santa, J. L. (1975). Verbal coding and redintegrative memory for shapes. Journal of Experimental Psychology: Human Learning and Memory, 104, 286-294. doi: 10.1037/0278-7393.1.3.286

Schneider-Garces, N. J., Gordon, B. A.. Brumback-Peltz, C. R., \& Shin, E. (2010). Span, CRUNCH, and beyond: Working memory capacity and the aging brain. Journal of Cognitive Neuroscience, 22, 655-669. doi: 10.1162/jocn.2009.21230 
Smith, A. D., Park, D. C., Cherry, K., \& Berkovsky, K. (1990). Age differences in memory for concrete and abstract pictures. Journal of Gerontology: Psychological Sciences, 45, 205-209. doi: 10.1093/geronj/45.5.P205

Smith, A. D., Park, D. C., Earles, J. L. K., Shaw, R. J., \& Whiting, W. L. IV. (1998). Age differences in context integration in memory. Psychology and Aging, 13, 21-28. doi: $10.1037 / 0882-7974.13 .1 .21$

Spreng, R. N., Wojtowicz, M., Grady, C. L. (2010). Reliable differences in brain activity between young and old adults: A quantitative meta-analysis across multiple cognitive domains. Neuroscience \& Biobehavioral Reviews, 34, 1178-1194. doi: 10.1016/j.neubiorev.2010.01.009

Swanson, H. L. (2017). Verbal and visual-spatial working memory: What develops over a life span? Developmental Psychology, 53, 971-995. doi: 10.1037/dev0000291

Tournier, I., \& Postal, V. (2011) Strategy selection and aging: Impact of item concreteness in paired-associate task. Aging, Neuropsychology, and Cognition, 18, 195-213. doi: $10.1080 / 13825585.2010 .525623$

Touron, D. R., Oransky, N., Meier, M. E., \& Hines, J. C. (2010) Metacognitive monitoring and strategic behaviour in working memory performance. The Quarterly Journal of Experimental Psychology, 63, 1533-1551. doi: 10.1080/17470210903418937

White, E. J., \& Grant, D. M. (2017). Electrocortical consequences of image processing: The influence of working memory load and worry. Psychiatry Research: Neuroimaging, 261, 1-8. doi: 10.1016/j.pscychresns.2017.01.003

Willis, S. L., Tennstedt, S. L., Marsiske, M., Ball, K., Elias, J., Koepke, K. M., ... Wright, E. (2006). Long-term effects of cognitive training on everyday functional outcomes in older adults. JAMA, 296, 2805-2814. Doi:10.1001/jama/296.23.2805

Vasques, R., Garcia, R. B., \& Galera, C. (2016). Short-term memory recall of visual patterns under static and dynamic visual noise. Psychology \& Neuroscience, 9, 46-53. doi: 10.1037/pne0000039

Verhaeghen, P., Palfai, T., \& Johnson, M. P. (2006). Verbal labeling as an assimilation mnemonic for abstract visual stimuli: The sample case of recognition memory for Chinese characters. Memory \& Cognition, 34, 795-803. doi: 10.3758/BF03193427 


\section{APPENDIX 1}

\section{Strategy Questionnaire}

1. In this task overall, please rate the extent to which you relied upon a visual and/or verbal strategy to help you remember the checkered patterns. A visual strategy involves concentrating on your mental image of what the pattern looks like. A verbal strategy involves verbalising the features of the pattern and concentrating on that verbal information.

1

"I used a verbal strategy only"
2

"I used mostly verbal but some visual rehearsal"
3

"I used verbal and visual strategies equally"
4

"I used mostly visual but some verbal rehearsal"

\section{5}

"I used a visual strategy only"

2. To what extent did you combine visual and verbal strategies to help remember individual patterns?
1
2
3
4
5
"Always"
"Most of the time"
"Sometimes"
"Rarely"
"Never"

3. To what extent did you "count up" the number of black cells?

$\begin{array}{ccccc}\mathbf{1} & \mathbf{2} & \mathbf{3} & \mathbf{4} & \mathbf{5} \\ \text { Always" } & \text { "Most of the time" } & \text { "Sometimes" } & \text { "Rarely" } & \text { "Never" }\end{array}$

4. To what extent did you attach verbal labels to some of the individual shapes? (e.g., naming a collection of black cells the letter " $L$ ")

$\begin{array}{ccccc}\mathbf{1} & \mathbf{2} & \mathbf{3} & \mathbf{4} & \mathbf{5} \\ \text { "Always" } & \text { "Most of the time" } & \text { "Sometimes" } & \text { "Rarely" } & \text { "Never" }\end{array}$

5. To what extent did you focus upon refreshing your mental image of the pattern?

1

"Always"
2

"Most of the time"
3

"Sometimes"
4

"Rarely"
5

"Never" 